Florida International University FIU Digital Commons

$11-15-2013$

\title{
Development of a Body for a Pneumatic Crawler for Radioactive Waste Pipelines
}

Jose Alfonso Matos

Jmato003@fiu.edu

DOI: $10.25148 /$ etd.FI13120910

Follow this and additional works at: https://digitalcommons.fiu.edu/etd

Part of the Mechanical Engineering Commons

\section{Recommended Citation}

Matos, Jose Alfonso, "Development of a Body for a Pneumatic Crawler for Radioactive Waste Pipelines" (2013). FIU Electronic Theses and Dissertations. 1026.

https://digitalcommons.fiu.edu/etd/1026

This work is brought to you for free and open access by the University Graduate School at FIU Digital Commons. It has been accepted for inclusion in FIU Electronic Theses and Dissertations by an authorized administrator of FIU Digital Commons. For more information, please contact dcc@fiu.edu. 


\section{FLORIDA INTERNATIONAL UNIVERSITY}

Miami, Florida

\section{DEVELOPMENT OF A BODY FOR A PNEUMATIC CRAWLER FOR RADIOACTIVE WASTE PIPELINES}

A thesis submitted in partial fulfillment of

the requirements for the degree of

MASTER OF SCIENCE

in

MECHANICAL ENGINEERING

by

Jose Alfonso Matos 
To: Dean Amir Mirmiran

College of Engineering and Computing

This thesis, written by Jose Alfonso Matos and entitled Development of a Body for a Pneumatic Crawler for Radioactive Waste Pipelines, having been approved in respect to style and intellectual content, is referred to you for judgment.

We have read this thesis and recommend that it be approved.

$\begin{array}{r}\hline \text { Igor Tsukanov } \\ \hline \text { Leonel Lagos } \\ \hline \text { Ibrahim Tansel, Major Professor }\end{array}$

Date of Defense: November 15, 2013

The thesis of Jose Alfonso Matos is approved.

Dean Amir Mirmiran College of Engineering and Computing

Dean Lakshmi N. Reddi University Graduate School

Florida International University, 2013 


\section{DEDICATION}

I dedicate this work to my wonderful parents Jose and Ramona Matos for their constant love and support, their many sacrifices, and for raising me to be the man I am today. 


\section{ACKNOWLEDGMENTS}

I would like to express my gratitude to Dr. Tansel, Dr. Tsukanov, and Dr. Lagos for their guidance, their humor, the lessons they have taught me over the years, and for serving on my committee. All were instrumental in aspects of my learning which have led to this thesis and have been of benefit in my new career. I would also like to thank Dr. Tosunoglu, who helped foster my interest in the field of robotics and helped guide the beginnings of this work. May he find peace, whatever he is going through, and I pray that we will see him again in the future. Tomas Pribanic led the crawler project at ARC and provided his expertise over the years, my appreciation goes to him for his help and for coming up with the idea. Amer Awwad and Jairo Crespo always supported me and taught me how to take on these types of projects, major thanks to them as well.

Thanks go to DOE's Office of Environmental Management for their support. I am also thankful to my friends in the DOE Fellow's program. All of them have contributed to my learning experience, in their own ways. In particular, I'd like to share my gratitude for Gabriela Vazquez, who was instrumental in helping me test both the previous crawler and my own. Also, to my friend Lee Brady, who got me involved with pipe crawlers, helped develop the original prototype, and always contributed a positive outlook.

Warm thanks go to my parents Jose and Ramona, my siblings Gabriela and Moises, my friends Jaime and Javier, my community group, and all my family and friends for their support, ideas, prayers, and love during this work. 


\author{
ABSTRACT OF THE THESIS \\ DEVELOPMENT OF A BODY FOR A PNEUMATIC CRAWLER FOR \\ RADIOACTIVE WASTE PIPELINES \\ by \\ Jose Alfonso Matos
}

Florida International University, 2013

Miami, Florida

Professor Ibrahim Tansel, Major Professor

The goal of this thesis was to develop a body for a crawler robot to navigate DOE Hanford Site transfer pipelines in a timely fashion. Previous work in pipe crawlers was analyzed and different configurations were studied by this author in order to design a suitable device. Tests were done in CAD to verify the device would fit and be able to travel within the confines of the pipelines'3" inner diameter and $90^{\circ}$ elbows with 4.25"radii. Pipelines in Hanford can transition into 2" pipe and this was also taken into consideration when selecting the dimensions for the device. Manufacturing methods and materials were selected in order to ensure minimal cost and time for manufacture. The manufactured device was tested for speed in straight sections and elbows, pulling force, and adaptability to changes in pipe dimension from 3" to 2". Modifications were made based on test results. 


\section{TABLE OF CONTENTS}

CHAPTER

PAGE

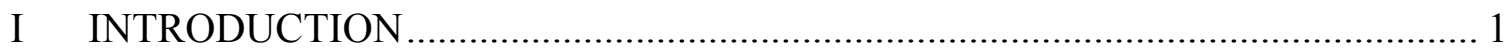

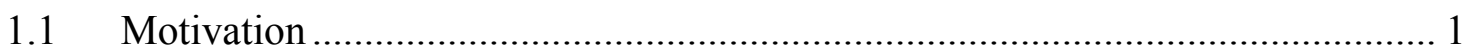

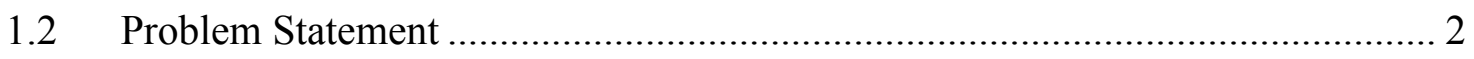

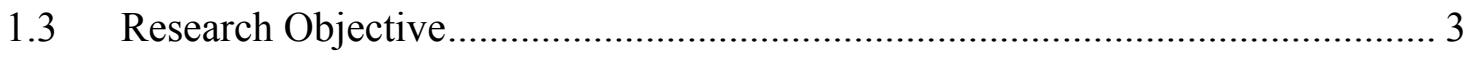

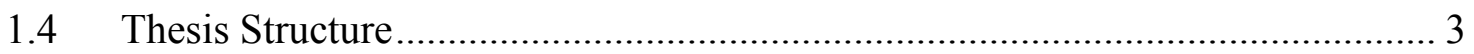

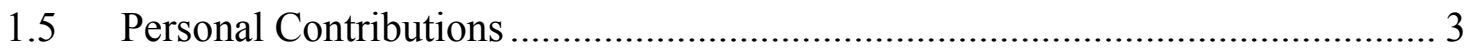

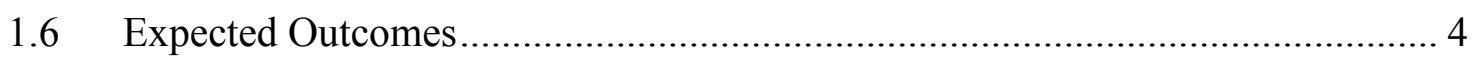

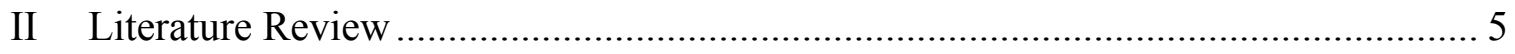

2.1 Varying Methods of Pipeline Unplugging ………....................................... 5

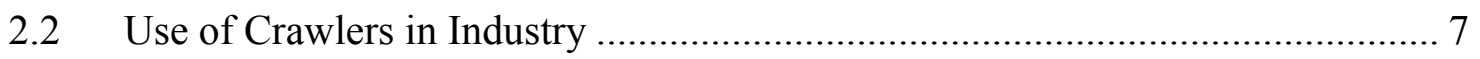

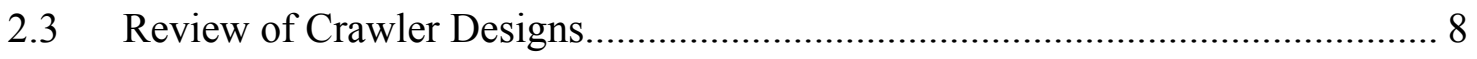

2.4 Materials in Radioactive Environments ………........................................... 12

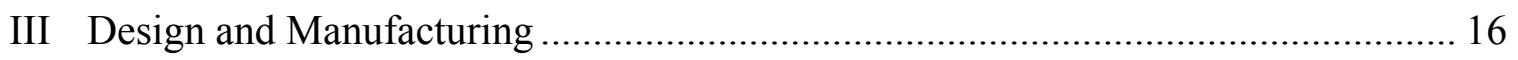

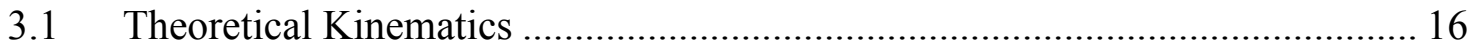

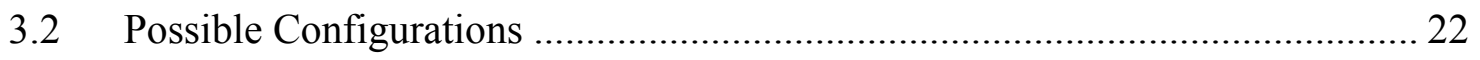

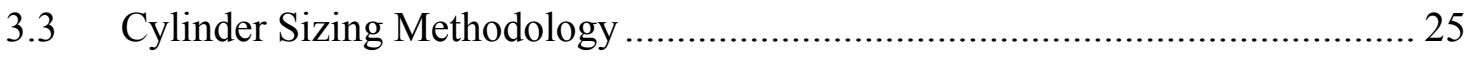

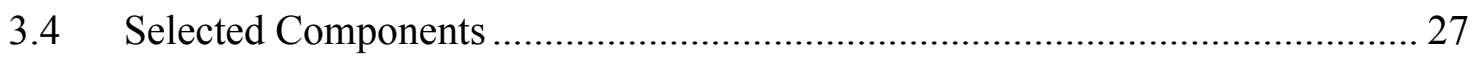

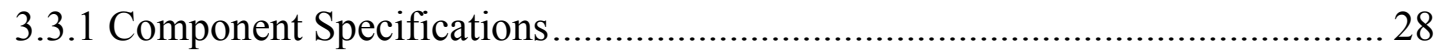

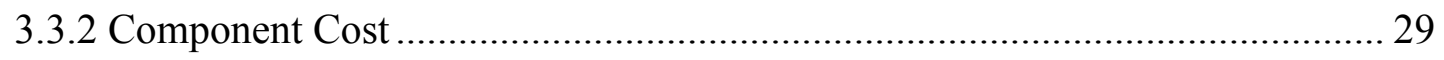

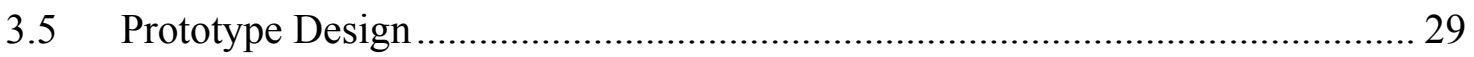

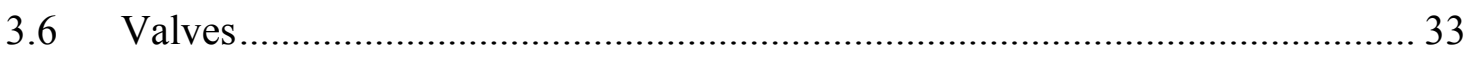

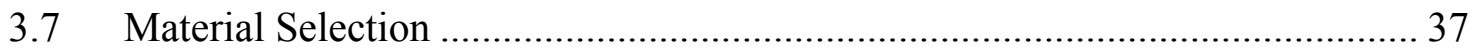

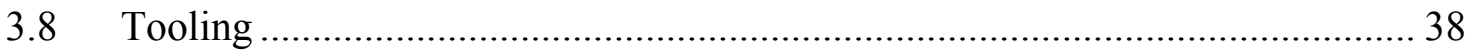

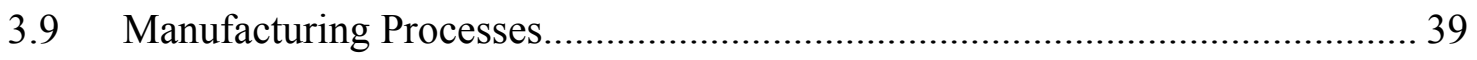

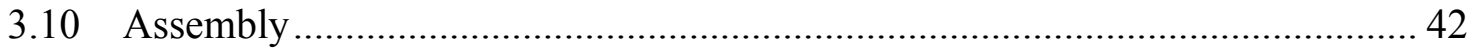

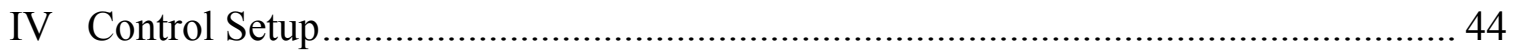

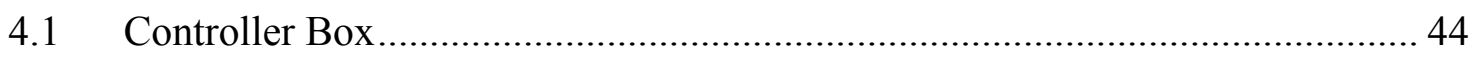

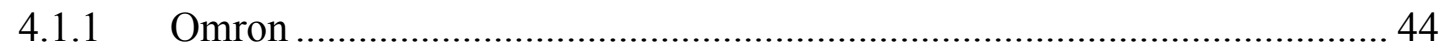

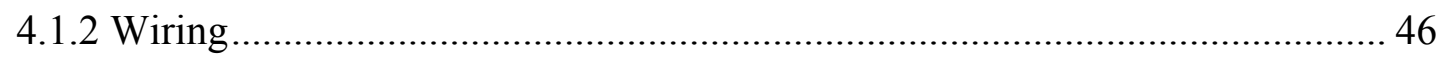

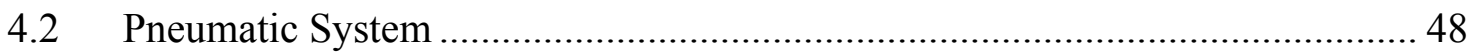

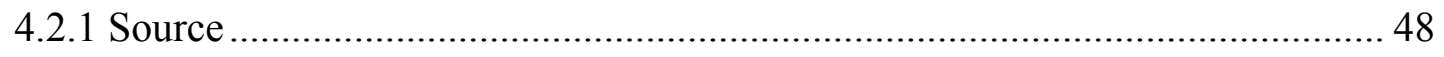

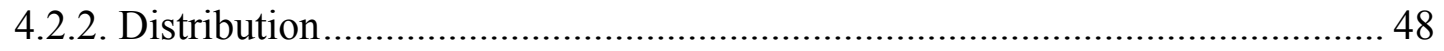




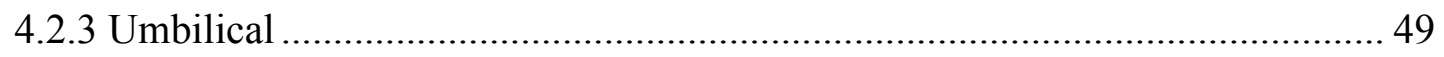

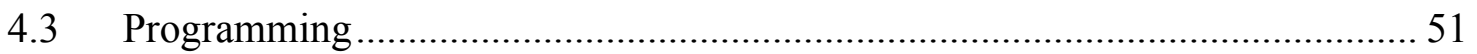

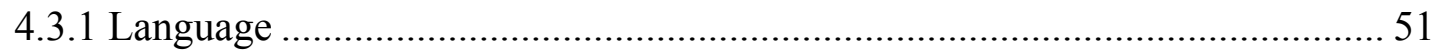

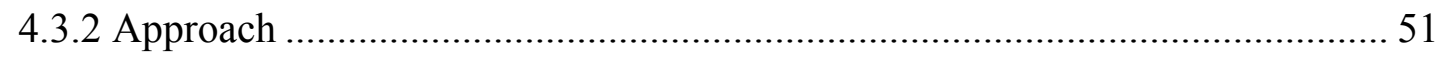

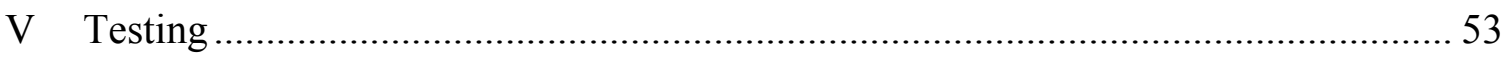

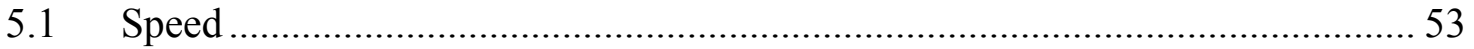

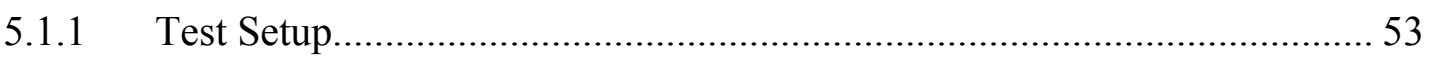

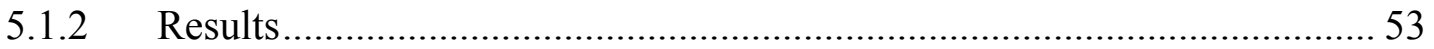

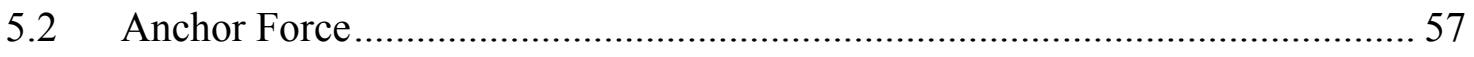

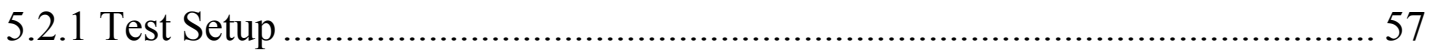

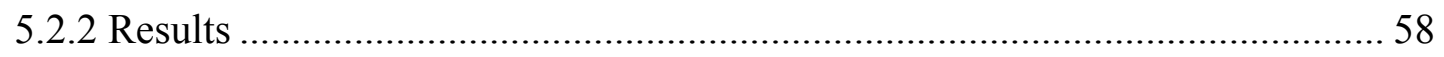

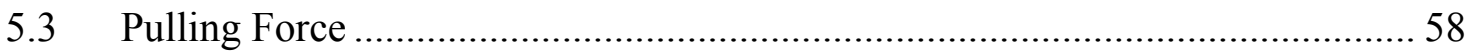

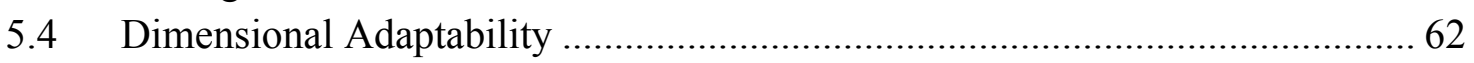

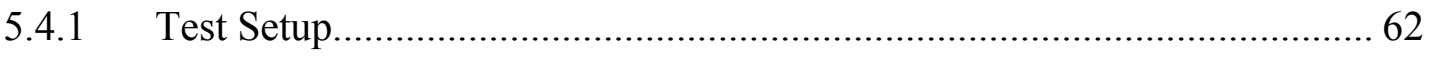

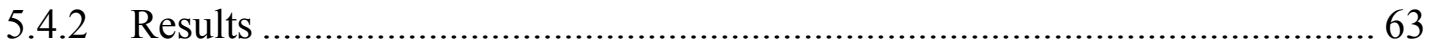

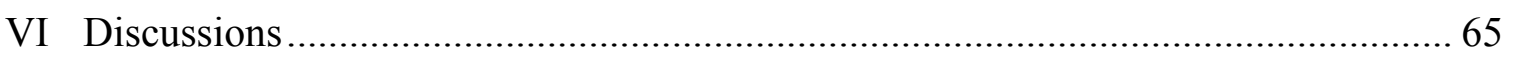

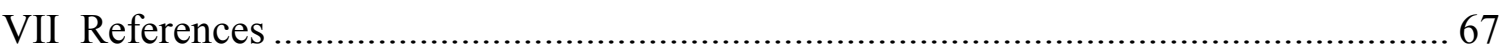

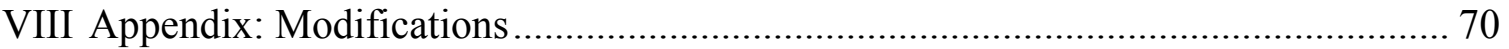




\section{LIST OF TABLES}

TABLE

PAGE

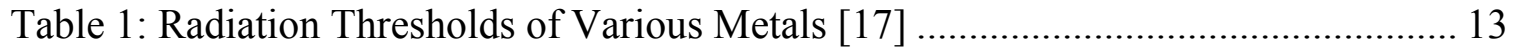

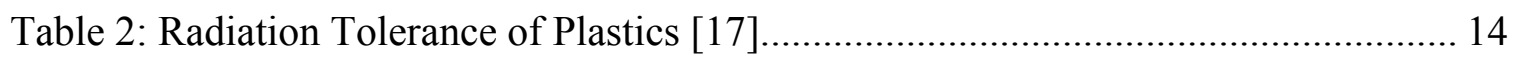

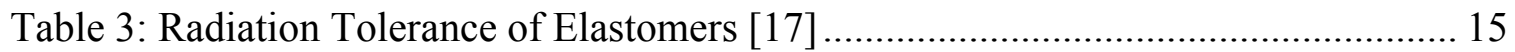

Table 4: Reference Table for Compression Factors and "A” Constants [18] .................. 26

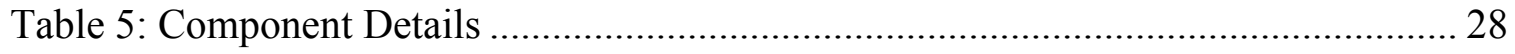

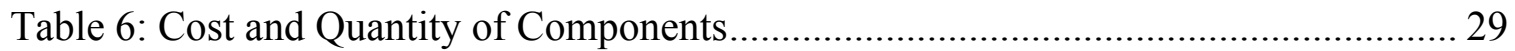

Table 7: Time to Reach Set Pressure vs. Tubing Length............................................ 34

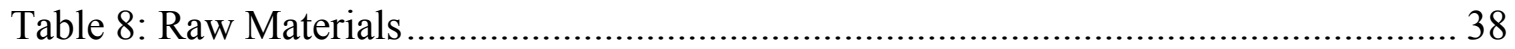

Table 9:Baseline Linear and Cornering Velocities ................................................ 54

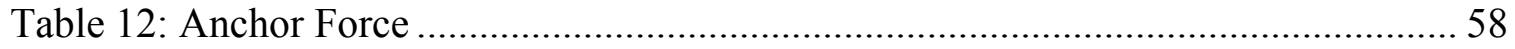

Table 13: Theoretical Linear Force Output .................................................................. 59

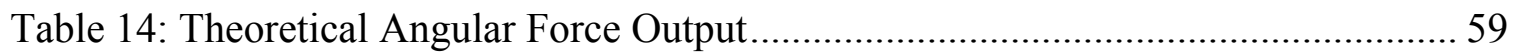

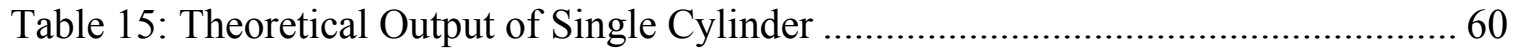

Table 16: Measured Output of Single Cylinder ..................................................... 61

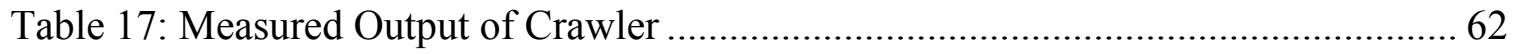

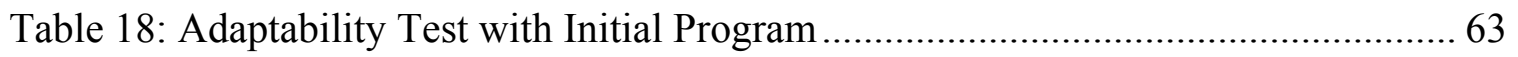

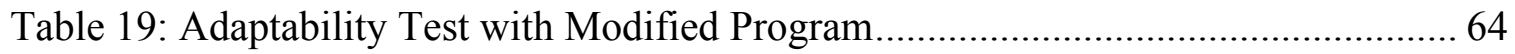




\section{LIST OF FIGURES}

$\begin{array}{ll}\text { FIGURE } & \text { PAGE }\end{array}$

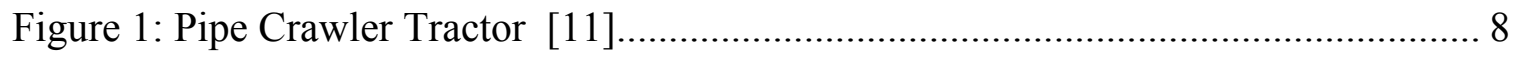

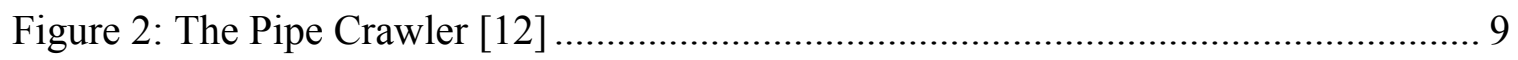

Figure 3: Pneumatically Operated Pipe Crawler [13] ........................................... 9

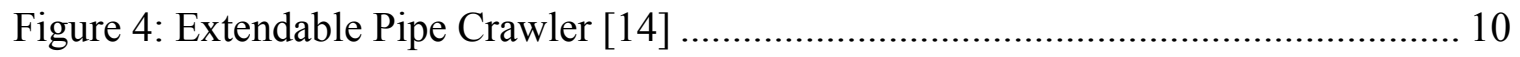

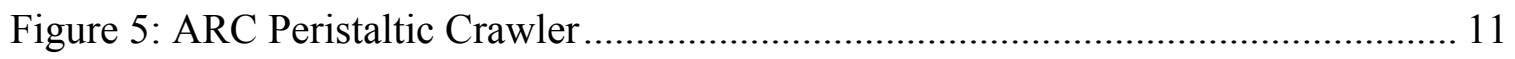

Figure 6: Diagram of Straight Line Kinematics ........................................................ 16

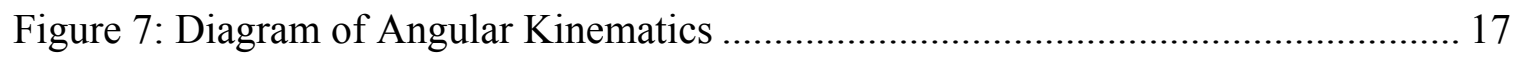

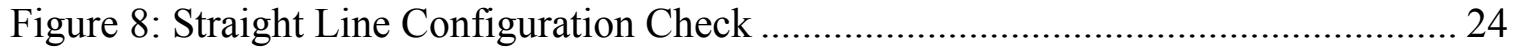

Figure 9: Maximum Allowable Package Size ............................................................. 25

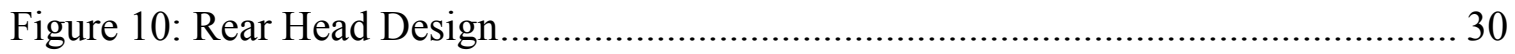

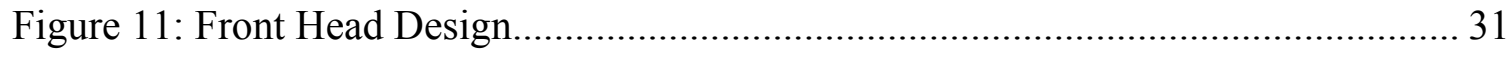

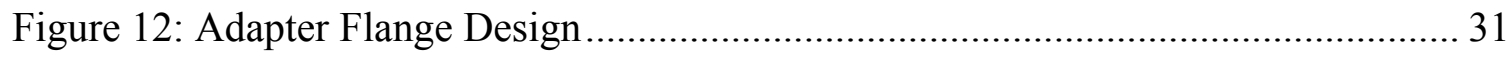

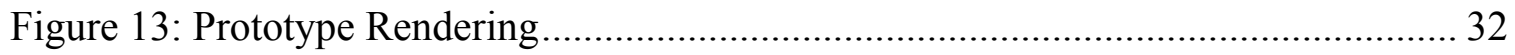

Figure 14: Depiction of Kinematics Through Elbow ................................................. 33

Figure 15: Mac Bullet Valve ${ }^{\circledR}$ with Anderson Powerpole ${ }^{\circledR}$ Connector ......................... 35

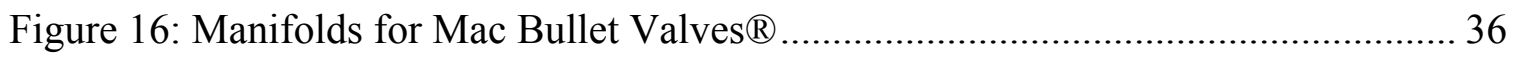

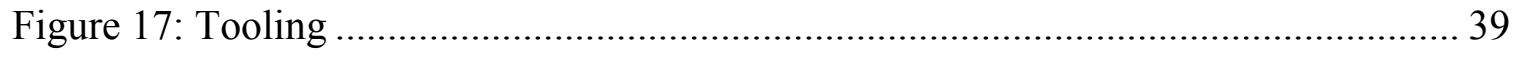

Figure 18: Freshly Turned Adapter Flanges ........................................................... 40

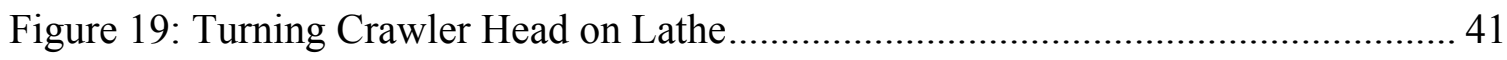

Figure 20: Completed Distribution Manifolds....................................................... 42

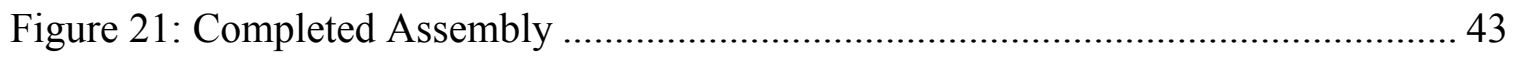




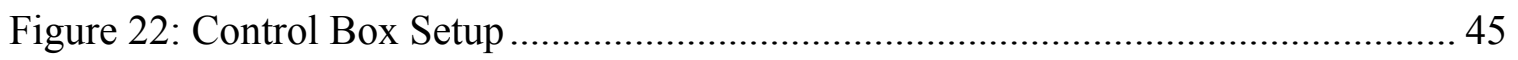

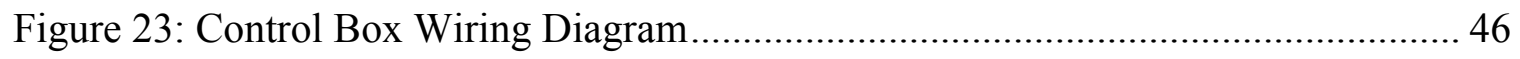

Figure 24: Pneumatic Diagram ............................................................................... 50

Figure 25: Screenshot of Ladder Program ...................................................................... 51

Figure 26: Linear Speed Results with PLC Program 1 ……........................................... 55

Figure 27: Cornering Speed Results with PLC Program 1 ........................................... 55

Figure 28: Linear Speed Results with PLC Program 2 ………………........................ 56

Figure 29: Cornering Speed Results with PLC Program 2 ………………………........ 56

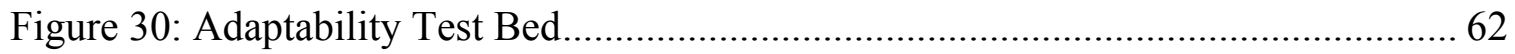




\section{INTRODUCTION}

\subsection{Motivation}

The main application being considered in this work is transfer pipelines for High Level Waste (HLW) at the Department of Energy (DOE) Hanford Site. This site in the state of Washington stores 56 million gallons of HLW within 177 underground tanks [1]. One hundred and forty nine of them are single-shell tanks, and some of these have been proven to leak, while others are suspected leakers [2]. DOE Environmental Management has addressed the issue by attempting to transfer waste to 28 double shell tanks via transfer pipes. The final goal is to transfer the waste to a waste treatment plant which will transform the waste into glass, a process called "vitrification."

Inside the treatment plant, the waste will pass through a concatenation of pipes. This has the potential to become an issue due to the waste being a slurry, its solids can settle and form a blockage [3]. The conventional method for addressing this problem is to identify the location of the blockage using inspection devices and send humans in protective suits to cut out the blocked sections and replace them. This approach is expensive and endangers lives, therefore it is not sustainable [4]. An alternative method is to flush chemicals through pipes in order to break down blockages. This is less than ideal because it generates more waste and further compounds the complex chemistries within Hanford waste.

Various unplugging technologies have been developed to approach this challenge. Unfortunately, they have met with limited success. The cause of this is that these unplugging technologies are less effective as the distances to blockages in the pipelines grow larger [5]. Therefore, a method that can reach and directly act upon a blockage 
would be ideal. This presents a challenge in which the application of robotics is desirable. A robot that can navigate these pipelines could eventually be employed as a platform to deliver unplugging tools.

\subsection{Problem Statement}

Unplugging of high level waste transfer pipelines can be a daunting task. The majority of technologies tested have been completely unsuccessful or only partially successful in providing unplugging alternatives to conventional repair methods. Distances to plugs, the elbows in the pipeline, changes in configuration such as reductions to 2 " pipe, and not knowing the distance to a plug can all create problems for unplugging a pipeline. As the pipelines are mostly underground and the documentation of changes made over the years is difficult to trace [4], the actual configuration of any given pipe will be difficult to model and perform simulations of.

Designing a robot which can travel within pipelines and deal with their configuration is a simpler alternative and test pipelines can be built to resemble possible conditions that may be found in pipelines. If such a robot can be made and tested, it could serve as a potential platform for future unplugging endeavors. The ideal robot would be able to navigate the pipelines at reasonable speeds and would be easy to repair if damaged. It should be comprised of materials with resistance to radioactive conditions. Finally, its design would need to be simple and robust, capable of being built by an average machine shop or factory at a low cost per unit. Use of commercially available components would aid in achieving a low cost. 


\subsection{Research Objective}

The primary objective of this research is to develop a robust crawler body which will be able to navigate within 3" pipes, transition into 2 " pipe, and move through $90^{\circ}$ elbows with a minimum radius of 4.25 "

The secondary objectives are:

- Design body such that robot is modular and may be easily repaired or setup for performing different tasks.

- Create a simple and robust controller setup to operate the crawler robot in order to minimize risk of control failure.

\subsection{Thesis Structure}

A literature review of past work in pipeline unplugging methods, robotic crawlers, and the Hanford Site and its challenges is presented in Chapter 2. Chapter 3 presents the possible physical configurations expected of the pipelines and the design and manufacturing work that was required to meet them. In Chapter 4, the layout, functioning, and programming format of the robot control setup is presented. In chapter 5, the various tests performed in order to validate the design, the required test setups, and test results are presented. Chapter 6 provides a discussion of the results achieved. The list of references used in this work is presented in Chapter 7. Chapter 8 presents the modifications made to improve performance as a result of testing.

\subsection{Personal Contributions}

1. A modular design that meets all physical requirements imposed by the 3 " inner diameter and 4.25" radius elbows in Hanford HLW pipelines 
2. Sizing, material selection, procurement of components, and manufacturing of robot

3. Experimental design and conduction of experiments

4. Modification of prototype based on test results and observations

\subsection{Expected Outcomes}

1. Development of a modular prototype which will achieve desirable results in the areas of speed, maneuverability, and reparability

2. Small but meaningful modifications to the structure and programming of the robot that will improve performance further 


\section{Literature Review}

\subsection{Varying Methods of Pipeline Unplugging}

A crawler robot is but one of a myriad of techniques used to unplug HLW pipelines. There are other technologies available which use various techniques from pulses in water or water pressure and other methods of pigging (inserting objects in the pipeline in order to push out blockages). These technologies have achieved limited success as they lose effectiveness when the distance to blockages increase or because they do not provide a full unplugging of the pipe [6].

$\mathrm{NuVision}$ Engineering Inc. developed a technology that functions on the principles of wave erosion. NuVision draws a vacuum in a pipeline up to the point where the blockage is located. It then fills the pipe with water up to the level of the blockage. Due to the fact that the vacuum is incomplete, some air is still caught in the pipe and the device takes advantage of this. It runs a series of pulses through the water, resulting in waves which wear away at the blockage. A solvent may be used in place of water if faster erosion is desired. Pipeline features, such as elbows, do not present a problem for this device. However, the action of the wave erosion, like that of erosion in nature, is rather slow. The aforementioned addition of solvents in place of water is not desirable, as it adds to the complex chemistries of Hanford waste [7].

A company by the name of The Atlantic Group developed a similar technology for pipeline unplugging. This device generates sound waves and amplifies them with water in order to cause the pipe and blockage to vibrate. Due to the different materials the pipe and blockage are comprised of, they will vibrate at different frequencies, dislodging the blockage from the pipe. This is achieved with sound waves at a frequency of 11,250 
vibrations/min and water which moves at $2100 \mathrm{ft} / \mathrm{s}$ [5]. Much like the device from $\mathrm{NuVision}$, this is not significantly limited by elbows, pipeline elements, or long lengths of pipe - although a longer distance to the blockage would cause some dampening of the frequency. Unfortunately, this method cannot deal with blockages which consist of dry salt crystals. Also, because they do not dissolve, it is possible for blockages to move down the pipe and become lodged in an elbow or other portion of the pipeline [7].

Other companies have developed more intrusive methods. Ridgid Tool Company developed a long flexible rod with a bladed end which can be used to cut up and break down blockages. This device is quite limited in that the rod is a mere $150 \mathrm{ft}$, its blades have been found to break against hard blockages, and the blades are not able to clear out an entire blockage [7]. This is only feasible for use in pipelines that are blocked near the entrance and is therefore not ideal in this application. An intrusive method that provides a better solution is that of a nozzle fed by a high pressure washer. Harben Inc. and Carolina Equipment and Supply both proposed solutions that use this method. Both consist of a high pressure washer, a water reservoir, a hose, and self-driving nozzle. Each device simply feeds its respective hose down the pipeline and up to the blockage. Harben Inc. has a washer providing 4,000 psi and Carolina Equipment \& Supply has one that provides 40,000 psi [7]. However, Harben Inc. included a machine that vibrates the hose to assist it in managing elbows. The device from Carolina Equipment \& Supply was found to stop moving forward after two elbows and even in straight pipes, it would stop after travelling $200 \mathrm{ft}$. Both devices fail against tougher blockages, as there is nothing to affix the nozzle in position, thus nothing prevents them from moving back as their jets hit the blockage [7]. 
The failure of these devices leaves a void which can be filled in with robotics. These methods, in particular the high pressure nozzles, show promise. Their drawbacks could be addressed with a device that could transport them to and hold them in place or even move them forward against a blockage. Crawler robots have been employed in the transportation of equipment in pipes and could prove to be a suitable solution for this problem.

\subsection{Use of Crawlers in Industry}

Pipe crawlers have been in use across a myriad of industries for many years. The most common application of a crawler is that of a pipeline inspection device. Nuclear power plants run hazardous substances through pipes and they use crawlers to inspect the condition of these pipes. Power plants that work under other principles also use crawlers to inspect for damages in pipes. Oil refineries and offshore drilling operations are required to maintain their piping due to safety and environmental concerns and have used crawlers to do this. Gasoline pipes, waste water systems, sewage treatment plants, chemical plants, and the food industry have a need to inspect and maintain pipelines and employ crawlers for these purposes [8].

These crawlers are generally equipped with cameras and light to allow the operator to perform visual inspection of the pipes. However, there are conditions which a camera may not reveal or cannot address and these are handled by other attachments. Lasers and ultrasonic wave generators may be mounted to a crawler in order to inspect for cracks, corrosion, and pipe wall thickness [8]. There are also attachments for dealing with imperfections or simply for smoothing pipe out. Certain industries require smooth surfaces inside pipes and imperfections in the pipes themselves, corrosion, and weld 
beads can pose a problem. In these cases, crawlers are equipped with milling and grinding tools which can correct these imperfections [8].

\subsection{Review of Crawler Designs}

There is an assortment of crawler designs as well as a variety of operating principles for them. Some, like the device developed in this thesis, are pneumatic whilst others are electronic or even hydraulic. Various patents and designs were reviewed and evaluated in order to guide the design process and develop the crawler robot for this thesis.

One such design is described in U.S. Patent 6035786. The device is described as a pipe crawler tractor and it uses an adaptable body and wheels to move through a pipe. A control system drives the wheels which contact opposed walls in the inside of the pipe. Each wheel is able to spin if needed and is mounted to a hinged track which is what allows for its flexibility through pipe elbows. [9]

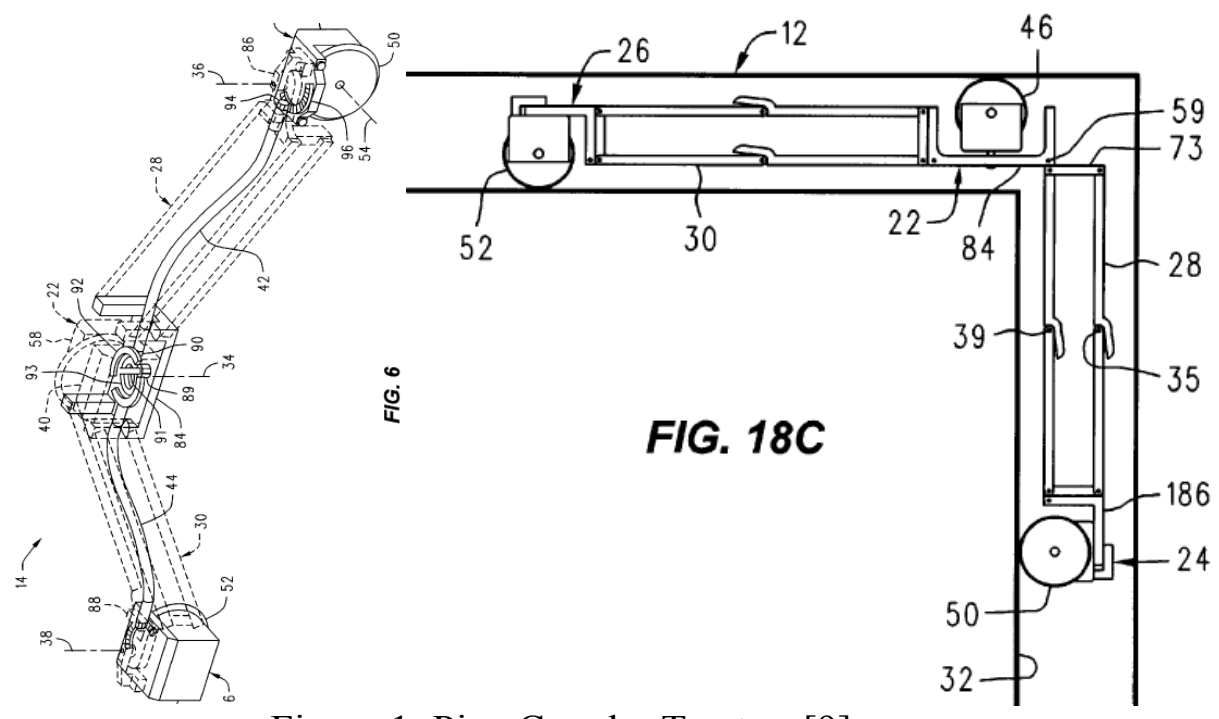

Figure 1: Pipe Crawler Tractor [9] 
Another crawler design that uses electricity to propel itself was built by a team of students at Florida Atlantic University. It was designed with the idea of being adaptable for various purposes spanning from pipeline inspection to locating survivors in collapsed buildings via their pipeline networks. It uses wheels mounted at angles in order to generate a helical, twisting motion through pipelines. A DC motor generates the spinning motion for the body [10].

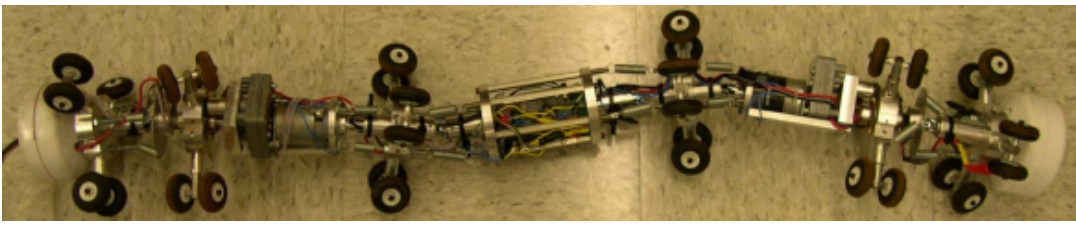

Figure 2: The Pipe Crawler [10]

U.S. Patent 4372161 depicts a device which uses a series of bladders in order to move through a pipe. The body itself does not change in length; rather the sequence of inflating and deflating bladders creates a forward motion. It was designed to move inspection equipment in a pipe [11].
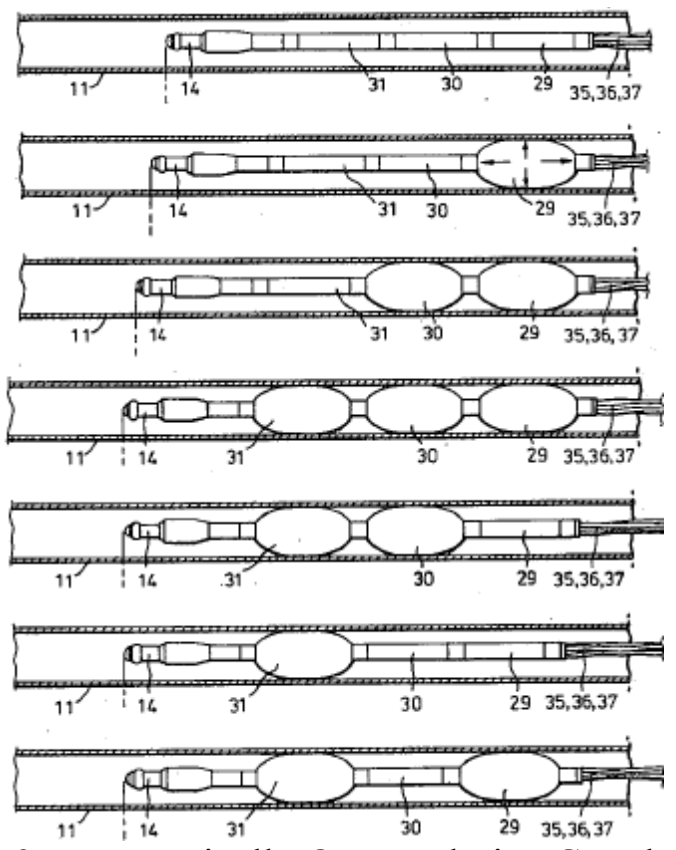

Figure 3: Pneumatically Operated Pipe Crawler [11] 
U.S. Patent 5018451 details a crawler that functions under an entirely different concept. This device is comprised of two pneumatic cylinders with a head on either end. Each head contains four cylinders with feet on their rods such that they can grab the pipe wall when extended. These provide traction whilst the pneumatic cylinders in center extend and collapse to provide locomotion. The heads are attached to these cylinders via hinges in order to allow the crawler to turn in elbows. It was designed to pull along inspection equipment to check pipes for cracks, corrosion, and welding defects [12].
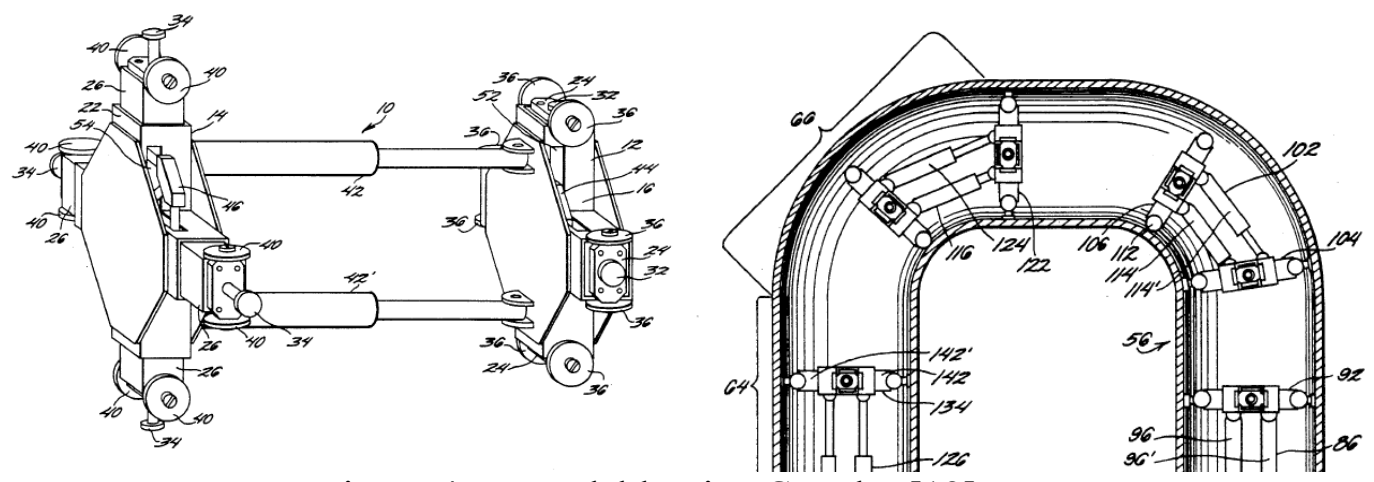

Figure 4: Extendable Pipe Crawler [12]

The Peristaltic Crawler project by the Applied Research Center (ARC) represents yet another approach at a crawler robot. This device uses a head with a bladder at either end in order to grab the pipe walls, and a bellows in center which expands and contracts to provide locomotion. It actually uses two bellows, installed concentrically in order to allow for a hollow center. This was done so that waste water could flow through the device during unplugging and in order to run the pressure hose for the nozzle [6]. A fiber optic line connected to a camera runs through the center of the current device along with the usual pressure hose. This device was designed explicitly for performing pipeline unplugging for HLW pipes and has met with some success in unplugging tests [13]. 


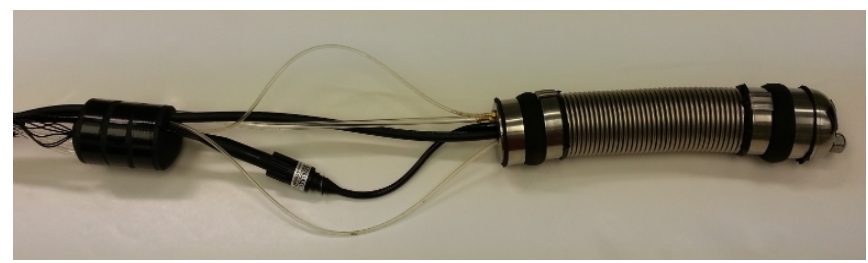

Figure 5: ARC Peristaltic Crawler

The crawler designs reviewed all present their own unique merits. US Patent 6035786 consists of a series of solid bodies hinged together and wheels used to traverse a pipe. Wheels were not considered ideal in the case of a pneumatic crawler for application at Hanford as they may lose traction. However, the combination of separate elements via hinges was of interest as this would allow freedom to bend in an elbow. Both US Patent 4372161 and the ARC crawler use bladders to grab the pipe walls. This provides a larger surface in contact with the pipe walls than small wheels. The benefit is improved anchor force in a pipe, helping these devices to avoid slippage under loads. However, the body of the ARC crawler uses a bellows, which was deemed less than ideal. This is due to its stiffness which makes it resistant to expansion, contraction, and bending. US Patent 5018451 contributed a possible solution in the form of pneumatic cylinders. The configuration presented is not ideal for application in Hanford as it only uses two cylinders to move forth and would be limited on force output. However, pneumatic cylinders were deemed an appropriate solution as they can provide large force output from a compact package. Due to the constraints imposed by the Hanford 3" ID piping and the force needed to pull an umbilical through them, a small body that can exert large forces is ideal. If attached to one another via hinges, as in US Patent 6035786, they could be placed in an arrangement flexible enough to traverse $90^{\circ}$ pipeline elbows. 


\subsection{Materials in Radioactive Environments}

Materials are a matter of primary concern for devices that are to be deployed in radioactive areas. Radiation has an adverse effect on electronics and can degrade material properties leading to failure of components and even the release of toxic material [14]. The main threat to a robot in this environment is exposure to gamma radiation [14]. Alpha and beta particles can be stopped by very light shielding and do not present a threat to a crawler robot. The Gray is a unit of measure typically used for X-rays and gamma rays. Measurements taken of Hanford waste tanks indicate that they emit an amount of gamma on the order of 10 Grays per hour (Gy/hr) [15]. The radiation in a transfer pipeline would be lower as the amount of waste within it would be lower. However, since this is the figure given, it would be ideal to select materials for a robot which can withstand these levels.

Metals in general present a viable solution to selecting materials for exposure to gamma rays. A very high dose of radiation accumulated over years will simply cause a loss in ductility whilst tensile and yield strength will increase [16]. These damages can then be fixed by annealing the metal. These benefits have made metals the most commonly used materials in the nuclear industry. The table below was created using data from "Designing equipment for use in gamma environments." 


\begin{tabular}{|c|c|c|}
\hline Metal & Threshold level (rad) & Threshold (Gy) \\
\hline Aluminum and Aluminum Alloys & $5 \times 10^{13}$ & $5 \times 10^{11}$ \\
\hline 300 Series SS & $1 \times 10^{13}$ & $1 \times 10^{11}$ \\
\hline 400 Series SS & $5 \times 10^{12}$ & $5 \times 10^{10}$ \\
\hline Iron & $3 \times 10^{12}$ & $3 \times 10^{10}$ \\
\hline Copper & $2 \times 10^{12}$ & $2 \times 10^{10}$ \\
\hline Brass and Bronze & $1 \times 10^{12}$ & $1 \times 10^{10}$ \\
\hline Nickel and Nickel Alloys & $1 \times 10^{12}$ & $1 \times 10^{10}$ \\
\hline Beryllium Copper & $6 \times 10^{11}$ & $6 \times 10^{9}$ \\
\hline
\end{tabular}

Table 1: Radiation Thresholds of Various Metals [16]

The values presented are thresholds. In simple terms, they represent the maximum accumulated dose a material can handle before it degrades due to the radiation. The chart indicates that aluminum and aluminum alloys have the highest resistance to gamma radiation of the metals listed, followed by 300 series SS. This resistance makes it feasible to manufacture deployment grade components for a crawler out of aluminum. This can produce a reduction in materials and manufacturing costs.

Also, fittings for use with pressurized air are generally made from metals, such as brass or stainless steel, but sometimes from certain types of plastics [14]. In the case of small elbow fittings, plastic would be a more common material; therefore, it is necessary to find which plastics would be suitable. Rigid plastics, generally made from heating or curing thermosetting plastic, can withstand more radiation than soft, thermoplastics. A common plastic in small fittings is polyethylene, in particular, high-density polyethylene (HDPE) which has a recommended service limit of $1 \times 10^{6}$ Gy [16]. The following table was found in "Designing Equipment for Use in Gamma Radiation Environments" and categorizes plastics based on levels of resistance to radiation. 


\begin{tabular}{|c|c|}
\hline Radiation Resistance & Plastic \\
\hline \multirow{9}{*}{ Highest } & glass-fiber phenolic \\
\hline & asbestos-filled phenolic \\
\hline & epoxy systems \\
\hline & polyurethane \\
\hline & polystyrene \\
\hline & mineral-filled polyester \\
\hline & mineral-filled silicone \\
\hline & furane resins \\
\hline & polyvinyl carbazole \\
\hline \multirow{6}{*}{ Moderate } & polyethylene \\
\hline & melamine-formaldehyde resin \\
\hline & urea-formaldehyde resin \\
\hline & aniline-formaldehyde resin \\
\hline & urfilled phenolic resin \\
\hline & silicone resin \\
\hline \multirow{5}{*}{ Poor } & methyl methacrylate \\
\hline & unfilled polyesters \\
\hline & cellulosic \\
\hline & polyamides \\
\hline & Teflon \\
\hline
\end{tabular}

Table 2: Radiation Tolerance of Plastics [16]

Acceptable elastomers must be found as well in order to select a material that can serve as bladders for the crawler robot. Elastomers exposed to radiation are typically subject to changes in tensile strength, compression set, and elongation properties [16]. The table below, taken from "Designing Equipment for Use in Gamma Radiation Environments," does not give tolerance figures; however, it indicates that among elastomers of interest for this application, polyurethane and natural rubber are in the range of the highest radiation resistance. Further reading revealed that natural rubber has an acceptable threshold of changes for elongation, tensile strength, and compression set of $5.5 \times 10^{4}, 2.4 \times 10^{5}$, and $2 \times 10^{4} \mathrm{~Gy}$. However, even butyl, the least radiation resistant of 
rubbers, was found to lose $25 \%$ of its tensile strength at $7 \times 10^{3}$ Gy and $50 \%$ at $3 \times 10^{4}$ Gy [16]. Readings from Hanford tanks indicate that tank waste generates around $10 \mathrm{~Gy} / \mathrm{hr}$ [15], thus even butyl could survive within pipelines (which have a lower gamma emission level due to lower waste concentration).

\begin{tabular}{|c|c|}
\hline Radiation Resistance & Rubber \\
\hline \multirow{6}{*}{ Highest } & polyurethane \\
\hline & natural \\
\hline & adduct \\
\hline & ethylene propylene \\
\hline & styrene-butadiene \\
\hline & Viton-A (in oil) \\
\hline \multirow{8}{*}{ Moderate } & Poly FBA \\
\hline & Cyanosilicate \\
\hline & vinyl pyride elastomer \\
\hline & acrylonitrile \\
\hline & nitrile \\
\hline & neoprene \\
\hline & Hypalon \\
\hline & Kel-F \\
\hline \multirow{4}{*}{ Poor } & silicone \\
\hline & polyacrylic \\
\hline & butyl \\
\hline & polysulfide (Thiokol) \\
\hline
\end{tabular}

Table 3: Radiation Tolerance of Elastomers [16] 


\section{Design and Manufacturing}

\subsection{Theoretical Kinematics}

The motion of the crawler robot can be broken down into two areas, motion in straight pipe and motion in an elbow. This analysis is simplified by eliminating the heads and simply analyzing the body. Thus, the analyzed robot will consist of four revolute joints and four prismatic joints. A revolute joint is a one- degree- of- freedom joint which allows for angular displacement. A prismatic joint is a one- degree- of- freedom joint which allows for linear displacement. The kinematics equations are developed with the crawler in expanded configuration for both motion in straight pipes and motion in elbows. Values for the collapsed configuration simply vary by a factor, that being the stroke length of the pneumatic cylinders.

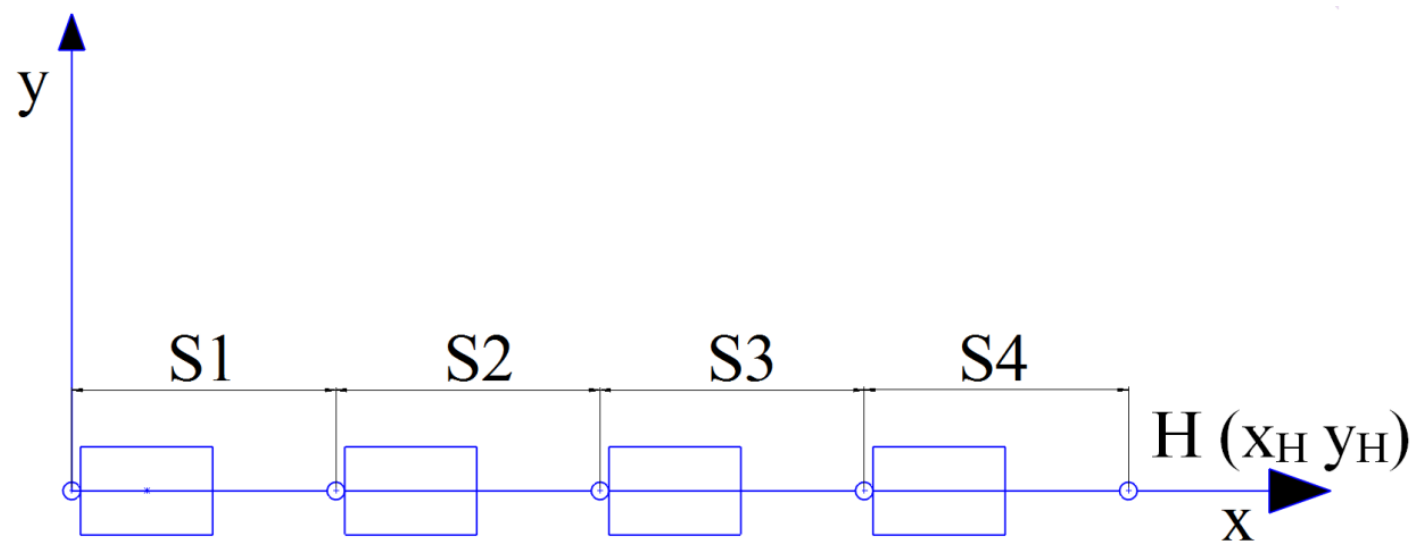

Figure 6: Diagram of Straight Line Kinematics

The position equations of the robot end effector in straight line motion are defined as

$x_{H}=S_{1}+S_{2}+S_{3}+S_{4}$

$y_{H}=0$

as there is no motion in the y direction

In this case, $S_{1}=S_{2}=S_{3}=S_{4}=S$ 
and thus

$x_{H}=4 S$

The velocity of vector of this robot's end effector is

$\left[\begin{array}{c}V_{H}^{x} \\ V_{H}^{y}\end{array}\right]=\left[\begin{array}{c}\frac{d y_{H}}{d S_{1}} \dot{S} \\ 0\end{array}\right]=\left[\begin{array}{c}4 \dot{S} \\ 0\end{array}\right]$

This velocity holds the same for both expanding and collapsing, thus if $\dot{S}$ is $1 \mathrm{in} / \mathrm{s}$, the robot configuration can expand at a velocity of $4 \mathrm{in} / \mathrm{s}$ and contract at a velocity of $4 \mathrm{in} / \mathrm{s}$. As contraction must take place before the next expansion, the robot will have shifted 4" overall in 2 seconds, one for expansion and one for contraction. This translates to the position of the front of the robot changing by 4 " in one expansion/contraction cycle, a theoretical velocity of $600 \mathrm{ft} / \mathrm{hr}$.

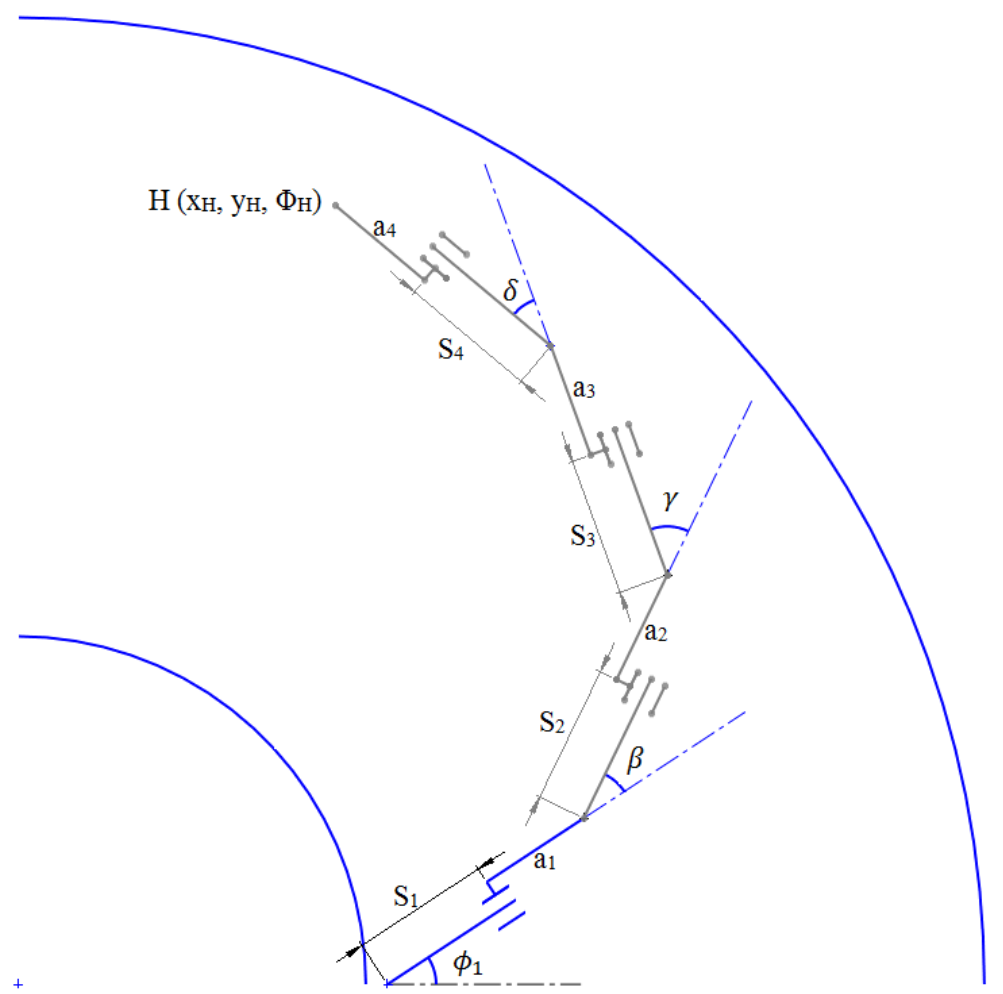

Figure 7: Diagram of Angular Kinematics 
The position equations of the robot in an elbow are defined as

$$
\begin{aligned}
& x_{H}=S_{1} \cos \phi_{1}+a_{1} \cos \phi_{1}+S_{2} \cos \left(\phi_{1}+\beta\right)+a_{2} \cos \left(\phi_{1}+\beta\right)+S_{3} \cos \left(\phi_{1}+\beta+\right. \\
& \gamma)+a_{3} \cos \left(\phi_{1}+\beta+\gamma\right)+S_{4} \cos \left(\phi_{1}+\beta+\gamma+\delta\right)+a_{4} \cos \left(\phi_{1}+\beta+\gamma+\delta\right) \\
& y_{H}=S_{1} \sin \phi_{1}+a_{1} \sin \phi_{1}+S_{2} \sin \left(\phi_{1}+\beta\right)+a_{2} \sin \left(\phi_{1}+\beta\right)+S_{3} \sin \left(\phi_{1}+\beta+\gamma\right)+ \\
& a_{3} \sin \left(\phi_{1}+\beta+\gamma\right)+S_{4} \sin \left(\phi_{1}+\beta+\gamma+\delta\right)+a_{4} \sin \left(\phi_{1}+\beta+\gamma+\delta\right) \\
& \Phi_{H}=\phi_{1}+\beta+\gamma+\delta
\end{aligned}
$$

In order to obtain the equations describing the velocity of the end effector in the elbow, the position equations are differentiated with respect to time. Let

$$
\begin{aligned}
& x_{H}=x_{H}\left(S_{1}, S_{2}, S_{3}, S_{4}, \phi_{1}, \beta, \gamma, \delta,\right) \\
& y_{H}=y_{H}\left(S_{1}, S_{2}, S_{3}, S_{4}, \phi_{1}, \beta, \gamma, \delta,\right) \\
& \Phi_{H}=\phi_{H}\left(S_{1}, S_{2}, S_{3}, S_{4}, \phi_{1}, \beta, \gamma, \delta,\right)
\end{aligned}
$$

Then,

$V_{H}^{x}=\dot{x}_{H}=\frac{\partial x_{H}}{\partial S_{1}} \dot{S}_{1}+\frac{\partial x_{H}}{\partial S_{2}} \dot{S}_{2}+\frac{\partial x_{H}}{\partial S_{3}} \dot{S}_{3}+\frac{\partial x_{H}}{\partial S_{4}} \dot{S}_{4}+\frac{\partial x_{H}}{\partial \phi_{1}} \omega_{1}+\frac{\partial x_{H}}{\partial \phi_{2}} \omega_{2}+\frac{\partial x_{H}}{\partial \phi_{3}} \omega_{3}+\frac{\partial x_{H}}{\partial \phi_{4}} \omega_{4}$

This can be rewritten as

$$
V_{H}^{\chi}=g_{H_{1}}^{x} \dot{S_{1}}+g_{H_{2}}^{\chi} \dot{S}_{2}+g_{H_{3}}^{\chi} \dot{S}_{3}+g_{H_{4}}^{x} \dot{S}_{4}+g_{H_{5}}^{\chi} \omega_{1}+g_{H_{6}}^{x} \omega_{2}+g_{H_{7}}^{\chi} \omega_{3}+g_{H_{8}}^{\chi} \omega_{4}
$$

In the same fashion,

$$
\begin{aligned}
& V_{H}^{y}=g_{H_{1}}^{y} \dot{S_{1}}+g_{H_{2}}^{y} \dot{S_{2}}+g_{H_{3}}^{y} \dot{S_{3}}+g_{H_{4}}^{y} \dot{S_{4}}+g_{H_{5}}^{y} \omega_{1}+g_{H_{6}}^{y} \omega_{2}+g_{H_{7}}^{y} \omega_{3}+g_{H_{8}}^{y} \omega_{4} \\
& \Omega_{H}=g_{H_{1}} \dot{S_{1}}+g_{H_{2}} \dot{S_{2}}+g_{H_{3}} \dot{S_{3}}+g_{H_{4}} \dot{S_{4}}+g_{H_{5}} \omega_{1}+g_{H_{6}} \omega_{2}+g_{H_{7}} \omega_{3}+g_{H_{8}} \omega_{4}
\end{aligned}
$$

Placing into matrix form, we obtain 
$\left[\begin{array}{l}V_{H}^{x} \\ V_{H}^{y} \\ \Omega_{H}\end{array}\right]=\left[\begin{array}{l}g_{H_{1}}^{x} g_{H_{2}}^{x} g_{H_{3}}^{x} g_{H_{4}}^{x} g_{H_{5}}^{x} g_{H_{6}}^{x} g_{H_{7}}^{x} g_{H_{8}}^{x} \\ g_{H_{1}}^{y} g_{H_{2}}^{y} g_{H_{3}}^{y} g_{H_{4}}^{y} g_{H_{5}}^{y} g_{H_{6}}^{y} g_{H_{7}}^{y} g_{H_{8}}^{y} \\ g_{H_{2}} g_{H_{3}} g_{H_{4}} g_{H_{5}} g_{H_{6}} g_{H_{7}} g_{H_{8}}\end{array}\right]\left[\begin{array}{c}\dot{S_{1}} \\ \dot{S_{2}} \\ \dot{S_{3}} \\ \dot{S_{4}} \\ \omega_{1} \\ \omega_{2} \\ \omega_{3} \\ \omega_{4}\end{array}\right]$

This follows the form

$\underline{V}_{H}=J \underline{\omega}$

Where

$V_{H}=\left[\begin{array}{c}V_{H}^{x} \\ V_{H}^{y} \\ \Omega_{H}\end{array}\right]$

$J=\left[\begin{array}{l}g_{H_{1}}^{x} g_{H_{2}}^{x} g_{H_{3}}^{x} g_{H_{4}}^{x} g_{H_{5}}^{x} g_{H_{6}}^{x} g_{H_{7}}^{x} g_{H_{8}}^{x} \\ g_{H_{1}}^{y} g_{H_{2}}^{y} g_{H_{3}}^{y} g_{H_{4}}^{y} g_{H_{5}}^{y} g_{H_{6}}^{y} g_{H_{7}}^{y} g_{H_{8}}^{y} \\ g_{H_{1}} g_{H_{2}} g_{H_{3}} g_{H_{4}} g_{H_{5}} g_{H_{6}} g_{H_{7}} g_{H_{8}}\end{array}\right]$

And

$\underline{\omega}=\left[\begin{array}{l}\dot{S_{1}} \\ \dot{S_{2}} \\ \dot{S_{3}} \\ \dot{S}_{4} \\ \omega_{1} \\ \omega_{2} \\ \omega_{3} \\ \omega_{4}\end{array}\right]$

The matrix $\underline{V}_{\mathrm{H}}$ represents the end effector velocities, $\underline{\omega}$ represents the joint velocities, and $\mathrm{J}$ is the Jacobian. The Jacobian transforms the joint velocities of $\underline{\omega}$ to the end effector velocities $\underline{\mathrm{V}}_{\mathrm{H}}$. The Jacobian dimensions are $3 \mathrm{xn}$ where $\mathrm{n}$ is the quantity of one degree of freedom joints in the section of the crawler body being analyzed.

Solving for the translational and rotational g-functions, we obtain 


$$
\begin{aligned}
g_{H_{1}}^{x}= & \frac{\partial x_{H}}{\partial S_{1}}=\cos \phi_{1}, g_{H_{2}}^{x}=\frac{\partial x_{H}}{\partial S_{2}}=\cos \left(\phi_{1}+\beta\right), g_{H_{3}}^{x}=\frac{\partial x_{H}}{\partial S_{3}}=\cos \left(\phi_{1}+\beta+\gamma\right), \\
g_{H_{4}}^{x}=\frac{\partial x_{H}}{\partial S_{4}}=\cos \left(\phi_{1}+\beta+\gamma+\delta\right), & \\
g_{H_{5}}^{x}=\frac{\partial x_{H}}{\partial \phi_{1}}= & -S_{1} \sin \phi_{1}-a_{1} \sin \phi_{1}-S_{2} \sin \left(\phi_{1}+\beta\right)-a_{2} \sin \left(\phi_{1}+\beta\right) \\
& -S_{3} \sin \left(\phi_{1}+\beta+\gamma\right)-a_{3} \sin \left(\phi_{1}+\beta+\gamma\right)-S_{4} \sin \left(\phi_{1}+\beta+\gamma+\delta\right) \\
& -a_{4} \sin \left(\phi_{1}+\beta+\gamma+\delta\right) \\
g_{H_{6}}^{x}=\frac{\partial x_{H}}{\partial \beta}= & -S_{2} \sin \left(\phi_{1}+\beta\right)-a_{2} \sin \left(\phi_{1}+\beta\right)-S_{3} \sin \left(\phi_{1}+\beta+\gamma\right) \\
& -a_{3} \sin \left(\phi_{1}+\beta+\gamma\right)-S_{4} \sin \left(\phi_{1}+\beta+\gamma+\delta\right) \\
& -a_{4} \sin \left(\phi_{1}+\beta+\gamma+\delta\right) \\
g_{H_{8}}^{x}=\frac{\partial x_{H}}{\partial \gamma}=- & -S_{4} \sin \left(\phi_{1}+\beta+\gamma+\delta\right)-a_{4} \sin \left(\phi_{1}+\beta+\gamma+\delta\right) \\
g_{H_{7}}^{x}=\frac{\partial x_{H}}{\partial \gamma}=- & -S_{3} \sin \left(\phi_{1}+\beta+\gamma\right)-a_{3} \sin \left(\phi_{1}+\beta+\gamma\right)-S_{4} \sin \left(\phi_{1}+\beta+\gamma+\delta\right) \\
&
\end{aligned}
$$

The second row of the Jacobian

$$
\begin{aligned}
g_{H_{1}}^{y}=\frac{\partial y_{H}}{\partial S_{1}}= & \sin \phi_{1}, g_{H_{2}}^{y}=\frac{\partial y_{H}}{\partial S_{2}}=\sin \left(\phi_{1}+\beta\right), g_{H_{3}}^{y}=\frac{\partial y_{H}}{\partial S_{3}}=\sin \left(\phi_{1}+\beta+\gamma\right), \\
g_{H_{4}}^{y}=\frac{\partial y_{H}}{\partial S_{4}}= & \sin \left(\phi_{1}+\beta+\gamma+\delta\right), \\
g_{H_{5}}^{y}=\frac{\partial y_{H}}{\partial \phi_{1}}= & S_{1} \cos \phi_{1}+a_{1} \cos \phi_{1}+S_{2} \cos \left(\phi_{1}+\beta\right)+a_{2} \cos \left(\phi_{1}+\beta\right) \\
& +S_{3} \cos \left(\phi_{1}+\beta+\gamma\right)+a_{3} \cos \left(\phi_{1}+\beta+\gamma\right)+S_{4} \cos \left(\phi_{1}+\beta+\gamma+\delta\right) \\
& +a_{4} \cos \left(\phi_{1}+\beta+\gamma+\delta\right)
\end{aligned}
$$




$$
\begin{aligned}
g_{H_{6}}^{y}=\frac{\partial y_{H}}{\partial \beta}= & S_{2} \cos \left(\phi_{1}+\beta\right)+a_{2} \cos \left(\phi_{1}+\beta\right)+S_{3} \cos \left(\phi_{1}+\beta+\gamma\right) \\
& +a_{3} \cos \left(\phi_{1}+\beta+\gamma\right)+S_{4} \cos \left(\phi_{1}+\beta+\gamma+\delta\right) \\
& +a_{4} \cos \left(\phi_{1}+\beta+\gamma+\delta\right) \\
g_{H_{7}}^{y}=\frac{\partial y_{H}}{\partial \gamma}= & S_{3} \cos \left(\phi_{1}+\beta+\gamma\right)+a_{3} \cos \left(\phi_{1}+\beta+\gamma\right)+S_{4} \cos \left(\phi_{1}+\beta+\gamma+\delta\right) \\
& +a_{4} \cos \left(\phi_{1}+\beta+\gamma+\delta\right) \\
g_{H_{8}}^{y}=\frac{\partial y_{H}}{\partial \gamma}= & S_{4} \cos \left(\phi_{1}+\beta+\gamma+\delta\right)+a_{4} \cos \left(\phi_{1}+\beta+\gamma+\delta\right)
\end{aligned}
$$

The third row of the Jacobian

$$
\begin{aligned}
& g_{H_{1}}^{y}=\frac{\partial \phi_{H}}{\partial S_{1}}=0, g_{H_{2}}^{y}=\frac{\partial \phi_{H}}{\partial S_{2}}=0, g_{H_{3}}^{y}=\frac{\partial \phi_{H}}{\partial S_{3}}=0, g_{H_{3}}^{y}=\frac{\partial \phi_{H}}{\partial S_{3}}=0, g_{H_{4}}^{y}=\frac{\partial \phi_{H}}{\partial S_{4}}=0 \\
& g_{H_{5}}^{y}=\frac{\partial \phi_{H}}{\partial \phi_{1}}=1, g_{H_{6}}^{y}=\frac{\partial \phi_{H}}{\partial \beta}=1, g_{H_{7}}^{y}=\frac{\partial \phi_{H}}{\partial \gamma}=1, g_{H_{8}}^{y}=\frac{\partial \phi_{H}}{\partial \delta}=1
\end{aligned}
$$

With these equations established, it is possible to specify the joint velocities, $\underline{\omega}$ and solve equation (17) in order to obtain the end effector velocities, $\underline{\mathrm{V}}_{\mathrm{H}}$. For demonstration, angular position values of $\phi 1=90, \beta=16, \gamma=17, \delta=15$, linear joint velocities of $1 \mathrm{in} / \mathrm{s}$, and rotational joint velocities of $1,2,3,1 \mathrm{rad} / \mathrm{s}$ are assumed. Using these values, the end effector velocities $V_{H}^{x}=-44.73 \mathrm{in} / \mathrm{s}, V_{H}^{y}=-26.04 \mathrm{in} / \mathrm{s}$, and $\Omega_{H}=7 \mathrm{rad} / \mathrm{s}$ are obtained. The negative values of the linear velocities indicate that the end effector is travelling in the opposite direction relative to the first link. This is accurate to the positioning of a crawler in an elbow. 


\subsection{Possible Configurations}

As per the kinematics, it was decided to run the cylinders in a straight line arrangement. This style is simple and only presents a challenge in running lines as the center no longer serves as a tunnel for them. For this reason, ports were designed into the rear head, which allow for pipes to run from the umbilical up to the cylinders and front head. Similar ports can be added to the front rim to allow for waste flow and running of lines for cameras or unplugging tools. However, the effectiveness of the unplugging method has already been verified, and this thesis focuses solely on improving the body that delivers the unplugging tool. For this reason, all designs and the final prototype were configured solely as inspection devices which could be used to verify the effectiveness of the body. A configuration for unplugging can be achieved by drilling the necessary ports and running the lines.

In order to keep controls simple and to reduce the number of air feed lines, the body was limited to four pneumatic cylinders. Double acting cylinders are ideal for this application as both expansion and contraction are handled by air pressure. A vacuum pump and slow vacuum cycles are thereby eliminated; however, this does mean that each cylinder requires two air lines to operate. Thus, the overall number of cylinders should be kept down to reduce excess hoses. Double acting cylinders also provide an advantage in reliability as the springs that retract single acting cylinders can fatigue over time.

The stroke length of the cylinder is important here because the stride length of each cycle plays into the overall speed of the crawler. Velocity is simply displacement over time, thus the greater the displacement per unit of time, the greater the velocity. However, the stroke of the cylinders is limited by the dimensions of the elbow. A long 
stroke means a long cylinder, and it becomes possible for them to wedge in the elbow and keep the crawler from moving forth. The thicker the cylinder, the more this becomes a problem. Cylinder bore is also an important factor because it determines the force output of the cylinder.

Theoretically, force is equal to the product of pressure and area, $F=P A$

In this case, the pressure is the inflation pressure in $1 \mathrm{~b} / \mathrm{in}^{2}$ (psi) and the area is the cross sectional area of the cylinder. This equation describes the force generated when a cylinder extends or performs an outstroke.

When it retracts, or instrokes, the force generation can be described as $F=P \pi \frac{\left(d_{1}^{2}-d_{2}^{2}\right)}{4}$

Where $\mathrm{d} 1$ is the diameter of the cylinder and $\mathrm{d} 2$ is the diameter of the rod [17]. This lower force is due to the smaller chamber area caused by the rod taking up space. In this application, the load is pulled forth by the outstroke; therefore, it is more important. Instroke force is mostly beneficial for keeping the rear from getting stuck as it moves forth. Air is a compressible fluid, such that these equations cannot accurately describe how much force is generated if the cylinder is under a load. However, industry standard approach in pneumatic cylinder sizing is to use these equations to oversize the system by $25 \%$ over the load being pushed by the pneumatics [17]. The amount of force required to pull an umbilical a set distance in these pipes is unknown; therefore the only available approach is to obtain the strongest cylinders that will fit within the pipelines. Inflation pressures are limited to 300 psi as per Hanford regulations, leaving cross sectional area as 
the only factor than can be increased. It is desirable then, to have as large of a bore as the pipe dimensions will allow.

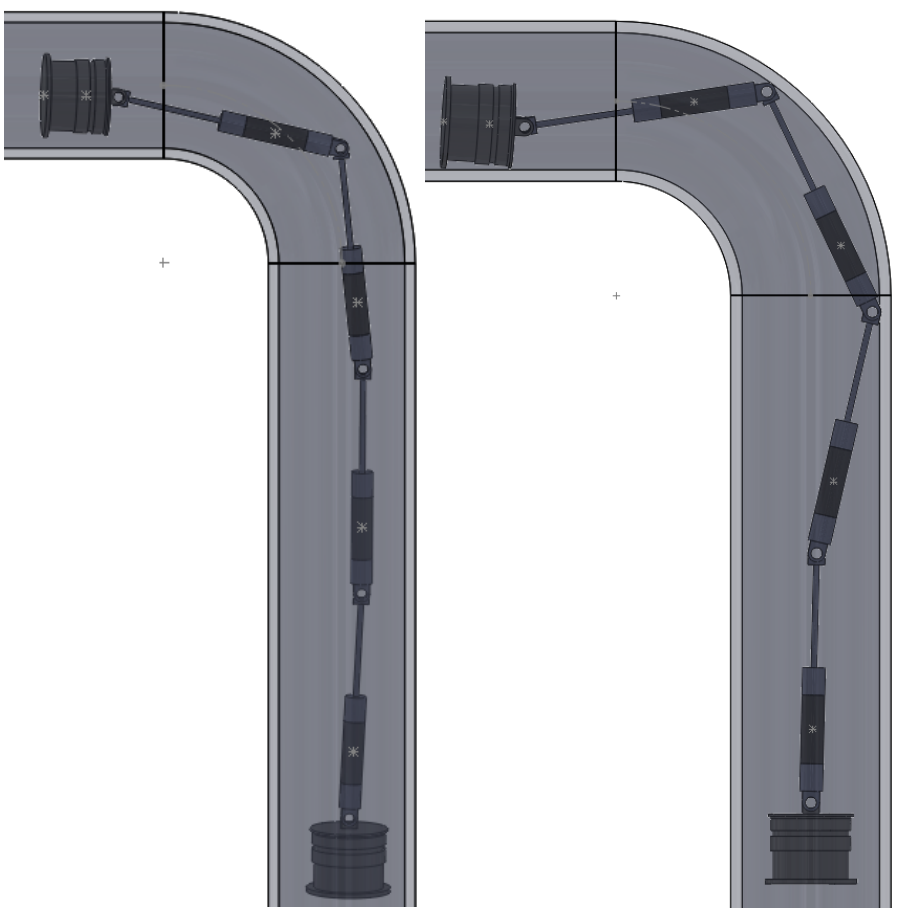

Figure 8: Straight Line Configuration Check

Looking at the images above, two possible ways for the crawler to move through an elbow are depicted. The scenario on the left is ideal, would allow the crawler to move through unhindered, and is also unlikely. The scenario on the right is more realistic as pushing against the wall of the elbow is what causes it to turn. Here, the importance of having a balance between length and diameter of the cylinders is evident. Already, the cylinders are likely to turn and get caught in the elbow walls. The cylinders modeled here have a stroke of 2.25 ," a cylinder length of 2.70 ," and a diameter of 0.5 ." The inner bore is 0.25 ," meaning that at $300 \mathrm{psi}$, these cylinders would output around $14.7 \mathrm{lb}$ of force. 


\subsection{Cylinder Sizing Methodology}

The need to balance the goal of maximum force output with the sizing and pressure constraints of the pipe requires that a sizing methodology be defined. This can be done by observing the method in which a cylinder could become wedged in an elbow and using this to determine a maximum package size. If the diagonal length of the cylinder is 3 " or greater, it has the potential to become wedged in the elbows. Using a diagonal length of $2.9, "$ a rectangle is drawn which contains the maximum package size possible. In turn, this sets a limit on the maximum possible bore and stroke the cylinder can have.

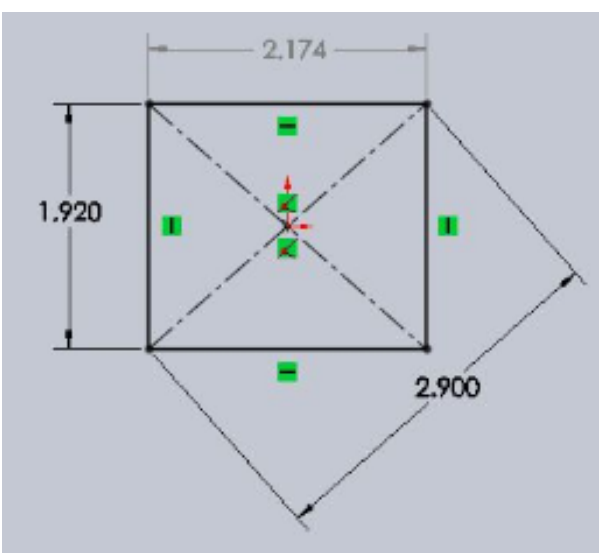

Figure 9: Maximum Allowable Package Size

The rectangle has lengths of 1.92" and 2.9." The 1.92" side is set as the limit for the diameter of the cylinder, such that it can pass through a 2" ID pipe. The limit on length of the cylinder is then $2.174 . "$ In this application, the cylinders will be hinged together, thus it is necessary that the hinge on each cylinder fit within the package size. Typically, compact cylinders are sold in $9 / 16,3 / 4,1 \frac{1}{16}, 1 \frac{1}{2}$, and 2 " bores. $1 \frac{1}{2}$ is the largest bore that fits within the package size, but the end caps would have a 2.62" OD. This leaves $3 / 4$ " bore which have end caps with $1.5 \% \mathrm{OD}$, this is within the package size. Compact 
cylinders with $3 / 4$ " bore come in stroke lengths of $0.5,0.75,1$, and 1.5." At 1.5" of stroke, the cylinder alone is 2.06 ," thus the addition of a hinge will exceed the package size. At 1 " stroke, the cylinder length is 1.56 ," allowing 0.614 " for the hinge. Therefore, the selected cylinder should have a bore of $3 / 4$ " and a stroke of $1 . "$

With the size of the cylinder selected, it is necessary to determine the appropriate valves for supplying them with air. The coefficient of velocity or $\mathrm{C}_{\mathrm{v}}$, a valve needs in order to feed a cylinder of a given dimension can be described by the following equation:

$C v=\frac{\operatorname{Area}(\text { Stroke }) A(C f)}{29(\text { Time })}[17]$

Where the unit for area is $i^{2}$, stroke is measured in inches, $\mathrm{A}$ is the pressure drop constant, and $\mathrm{C}_{\mathrm{f}}$ is the compression factor. The pressure drop constant and compression factor may be obtained in the following table:

\begin{tabular}{|c|c|c|c|c|}
\hline \multirow{2}{*}{ Inlet Pressure (PSI) } & \multirow{2}{*}{ Cf Compression Factor } & \multicolumn{4}{|c|}{ "A" Constant for various pressure drops } \\
\cline { 3 - 5 } & & 2 PSI $\Delta \mathrm{P}$ & $5 \mathrm{PSI} \Delta \mathrm{P}$ & $10 \mathrm{PSI} \Delta \mathrm{P}$ \\
\hline 10 & 1.6 & & 0.102 & \\
\hline 20 & 2.3 & 0.129 & 0.083 & 0.066 \\
\hline 30 & 3 & 0.113 & 0.072 & 0.055 \\
\hline 40 & 3.7 & 0.097 & 0.064 & 0.048 \\
\hline 50 & 4.4 & 0.091 & 0.059 & 0.043 \\
\hline 60 & 5.1 & 0.084 & 0.054 & 0.04 \\
\hline 70 & 5.7 & 0.079 & 0.05 & 0.037 \\
\hline 80 & 6.4 & 0.075 & 0.048 & 0.035 \\
\hline 90 & 7.1 & 0.071 & 0.045 & 0.033 \\
\hline 100 & 7.8 & 0.068 & 0.043 & 0.031 \\
\hline 110 & 8.5 & 0.065 & 0.041 & 0.03 \\
\hline 120 & 9.2 & 0.062 & 0.039 & 0.029 \\
\hline
\end{tabular}

Table 4: Reference Table for Compression Factors and "A" Constants [17] 
The "A" values used for critical applications are found in the 2 PSI $\Delta \mathrm{P}$ column [17]. Assuming 120 psi inflation, the corresponding $C_{f}$ is 9.2 and the " $A$ " constant is 0.062 . Using these values with the desired dimensions of 0.75 " bore and 1 " stroke, the required $\mathrm{C}_{\mathrm{v}}$ for operating each cylinder for 10 seconds is $0.869 \times 10^{-3}$. In order to limit complexity, all four cylinders should be fed by one valve. This means the valve would need four times the $\mathrm{C}_{\mathrm{v}}$, or $3.476 \times 10^{-3}$.

\subsection{Selected Components}

In order to reduce manufacturing costs and time, a point was made to use as many commercially available components as possible. Pneumatic cylinders are commercially available in a variety of specifications to meet the requirements of several different applications. Nitra ${ }^{\mathrm{TM}}$ produces a micro pneumatic cylinder with a $3 / 4$ " bore and a 1 " stroke with an O.D. of just 1.5" and a length of 1.56," making it ideally sized for this application. Furthermore, with a maximum inflation pressure of 250 psi it is capable of producing a force of $110.4 \mathrm{lbs}$ on outstroke. Each weighs in at a mere $0.17 \mathrm{lbs}$. The company markets a set of rod eyes which thread into the rod on the cylinders using a 1032UNF thread and a clevis bracket for these. However, the clevis bracket is not made to attach to the back of one of the cylinders, creating an array of them as in this application. For this reason, a set of flanges had to be designed and manufactured to adapt a clevis bracket to the back of each cylinder that needed it. 


\subsubsection{Component Specifications}

\begin{tabular}{|c|c|c|}
\hline Manufacturer/Vendor & Part\# & Description \\
\hline Nitra & C12010D & $\begin{array}{l}\text { Double acting pneumatic cylinder with a } 304 \text { stainless } \\
\text { steel body, 1" stroke, } 3 / 4 \text { " bore, single end rod, and } 10 \text { - } \\
32 \text { female ports }\end{array}$ \\
\hline Nitra & CCB-17 & $\begin{array}{l}\text { Anodized aluminum clevis bracket with } 304 \text { stainless } \\
\text { steel pin }\end{array}$ \\
\hline Nitra & CRP-12 & $\begin{array}{l}\text { Zinc plated alloy steel rod eye with } 10-32 \text { threaded } \\
\text { end and eye with bronze pivot bushing }\end{array}$ \\
\hline Clippard & MEV-2 & $\begin{array}{l}\text { Miniature quick exhaust valve with 10-32 threaded } \\
\text { ends }\end{array}$ \\
\hline McMaster & 92185A144 & socket head screw, 1/4" long with 6-32 thread \\
\hline McMaster & 92185A148 & 316 SS Socket head screw, $1 / 2$ " long with 6-32 thread \\
\hline McMaster & 92185A161 & 316SS socket head screw, 1-3/4" long with 6-32 \\
\hline McMaster & $5423 \mathrm{~K} 13$ & 201SS low profile hose clamp, 3/8" wide \\
\hline McMaster & $5454 \mathrm{~K} 61$ & $\begin{array}{l}\text { Miniature brass male connector fitting, } 10-32 \text { thread, } \\
1 / 16 \text { " hose barb }\end{array}$ \\
\hline McMaster & 92949A259 & 18-8SS socket cap screw, 10-32 thread, 3/16" long \\
\hline Parker & $28-4-10 \times 32$ & $\begin{array}{l}\text { Brass male connector, } 10-32 \text { thread, barb for } 1 / 4 \text { " tube, } \\
150 \text { psi maximum pressure }\end{array}$ \\
\hline Eldon James & L1032-1HDPE & $\begin{array}{l}\text { High density polyethylene male } 90^{\circ} \text { elbow, } 10-32 \\
\text { thread and } 1 / 16^{\prime} \text { hose barb, } 260 \text { psi maximum } \\
\text { pressure, high chemical resistance }\end{array}$ \\
\hline Pneumadyne & EB10 & $\begin{array}{l}\text { Brass male connector, } 10-32 \text { thread and } 1 / 16^{\prime \prime} \text { hose } \\
\text { barb, maximum pressure } 125 \mathrm{psi} @ 75^{\circ} \mathrm{F}\end{array}$ \\
\hline Sunlite & 6321 & 26x1.95-2.35 butyl inner tube, heavy duty \\
\hline
\end{tabular}

Table 5: Component Details 


\subsubsection{Component Cost}

\begin{tabular}{|c|c|c|c|c|c|}
\hline Manufacturer/Vendor & Part \# & Unit & Cost per & Quantity & Overall Cost \\
\hline Nitra & C12010D & ea & 38 & 4 & 152 \\
\hline Nitra & CCB-17 & ea & 16 & 5 & 80 \\
\hline Nitra & CRP-12 & ea & 11 & 5 & 55 \\
\hline Clippard & MEV-2 & ea & 6.21 & 2 & 12.42 \\
\hline McMaster & 92185A144 & pk. 25 & 2.36 & 1 & 2.36 \\
\hline McMaster & 92185A148 & pk. 25 & 2.5 & 1 & 2.5 \\
\hline McMaster & 92185A161 & pk. 10 & 5.54 & 2 & 11.08 \\
\hline McMaster & $5423 \mathrm{~K} 13$ & pk. 8 & 14.09 & 2 & 28.18 \\
\hline McMaster & 5454K61 & pk. 10 & 7.8 & 1 & 7.8 \\
\hline McMaster & 92949A259 & pk. 50 & 7.8 & 1 & 7.8 \\
\hline Parker & $28-4-10 \times 32$ & ea & 2.17 & 2 & 4.34 \\
\hline Eldon James & L1032-1HDPE & Pk. 10 & 9.79 & 1 & 9.79 \\
\hline Pneumadyne & EB10 & ea & 1.26 & 2 & 2.52 \\
\hline Sunlite & 63390 & ea & 6.99 & 1 & 6.99 \\
\hline & & & & Total & 382.78 \\
\hline
\end{tabular}

Table 6: Cost and Quantity of Components

\subsection{Prototype Design}

With the selected components and their specifications known, a design of the prototype was put together in SolidWorks ${ }^{\circledR}$. The cylinders were mated to the clevis brackets via the adapter flanges on their closed end and to the rod eyes on their rod ends. With this assembly complete, measurements were taken in order to design a set of heads that would be appropriate for the prototype. The heads were designed such that the sections with largest diameter would be 1.75," allowing for a smooth transition into 2" pipe. Each head consists of a cylinder with a lip on either end for keeping clamps from sliding off and a port which runs axially from one face through to the center line of the head where it meets with a perpendicular port. This port exits radially out to the circumference of the cylinder. These ports were sized for a \#21 drill bit to allow for a 1032 thread to be cut into the face of each head. A central groove is made around the 
circumference at the point where the port is, in order to dissipate air even when the bladder material is tight against the head. From here, each head has adaptations based on what is needed at its location.

The rear head has two ports running axially through it in order to allow for air lines to be run to the cylinders. On the face where it meets the cylinders, it also has a threaded hole for threading it onto the nearest cylinder.

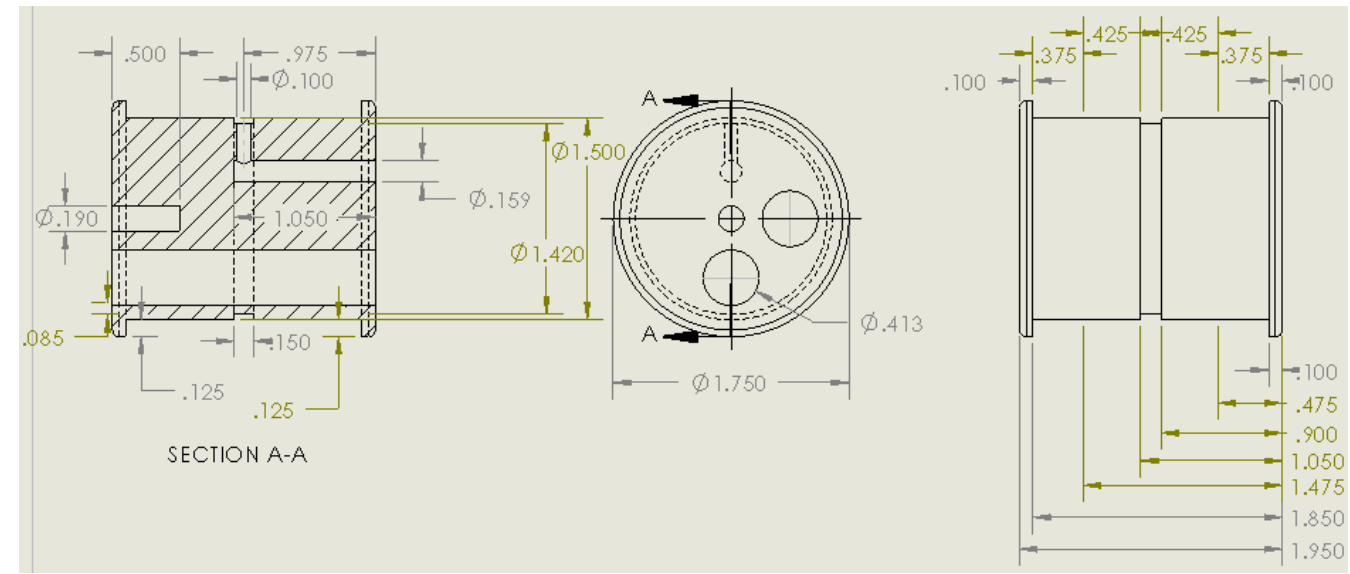

Figure 10: Rear Head Design

The front head has four threaded holes near the air port for attaching it to the clevis bracket of the cylinder on that end. This clevis bracket is notched to allow clearance for the fitting that goes into this air port. 


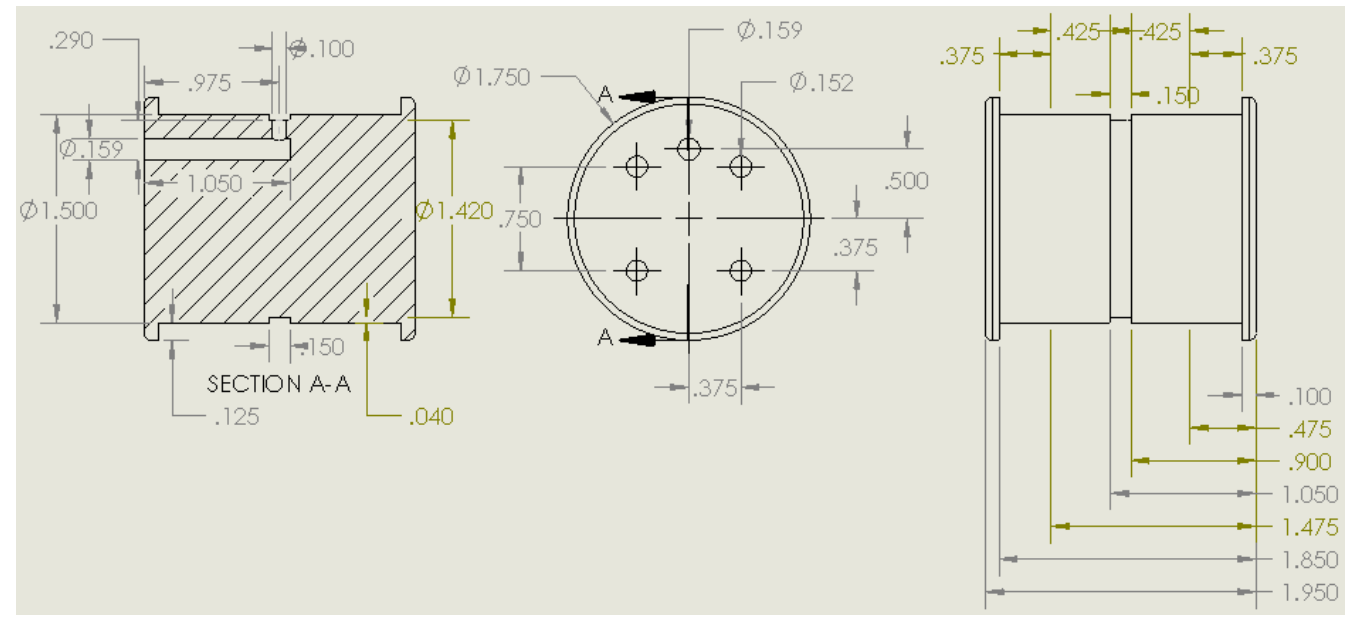

Figure 11: Front Head Design

The aforementioned adapter flanges each consist of an aluminum disk with eight holes drilled in. The holes are arranged in two patterns of four holes each. One hole pattern corresponds to the hole pattern on the clevis bracket, whereas the other pattern corresponds to that of the pneumatic cylinder. These holes were sized for a $\# 36$ drill bit to allow for cutting them to a 6-32 thread.

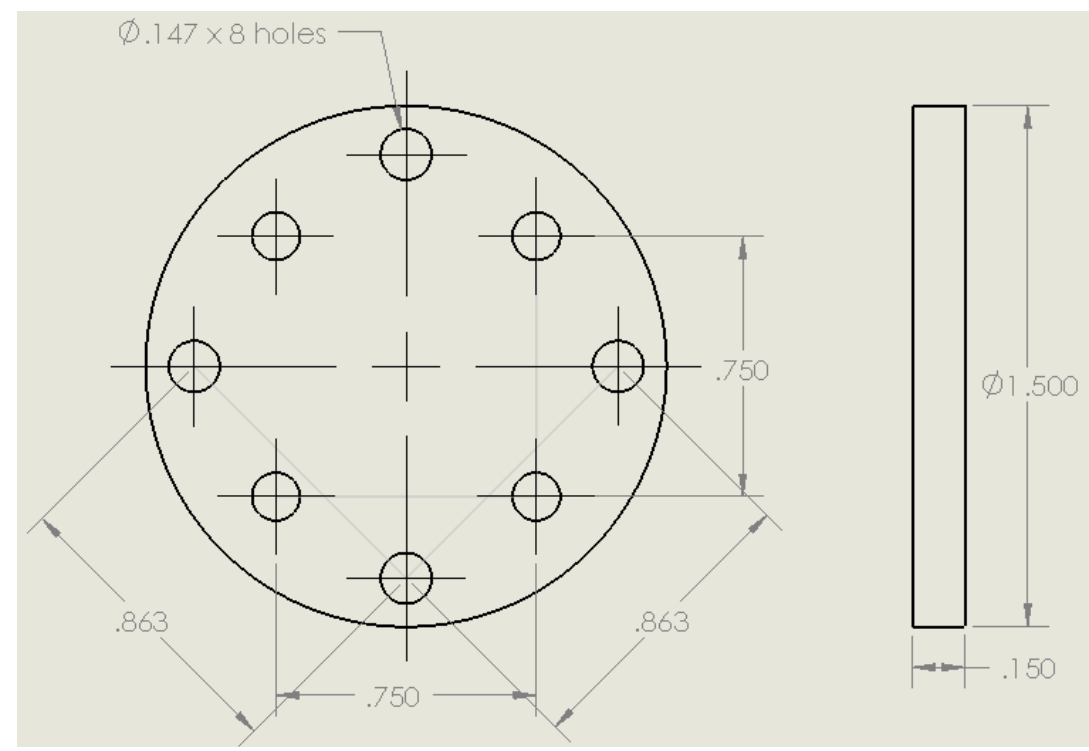

Figure 12: Adapter Flange Design

The final assembly has an appearance similar to a set of vertebrae. It has a collapsed length of approximately 17 " and an expanded length of 21. ." The 1" stroke adds 
up over the four cylinders to provide the prototype with a 4" stroke. The figure below is an image of what the prototype will look like.

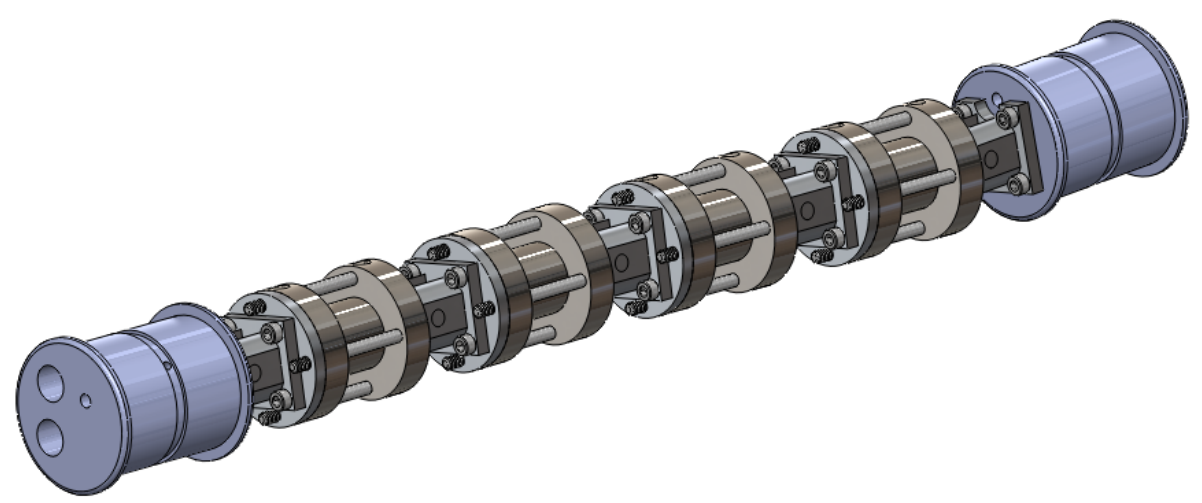

Figure 13: Prototype Rendering

These dimensions allow for a design which can move through a regulation Hanford elbow without obstruction. Provided the bladders can expand enough to grip the pipes, the 1.75 " maximum O.D. of the prototype will not pose a problem in the 3" I.D. pipe. This maximum diameter also leaves 0.25 " of clearance to move through a 2 " I.D. pipe. The prototype design was tested in an elbow in SolidWorks ${ }^{\circledR}$ and also in a pipeline which transitions from 3" to 2" I.D. pipe. 


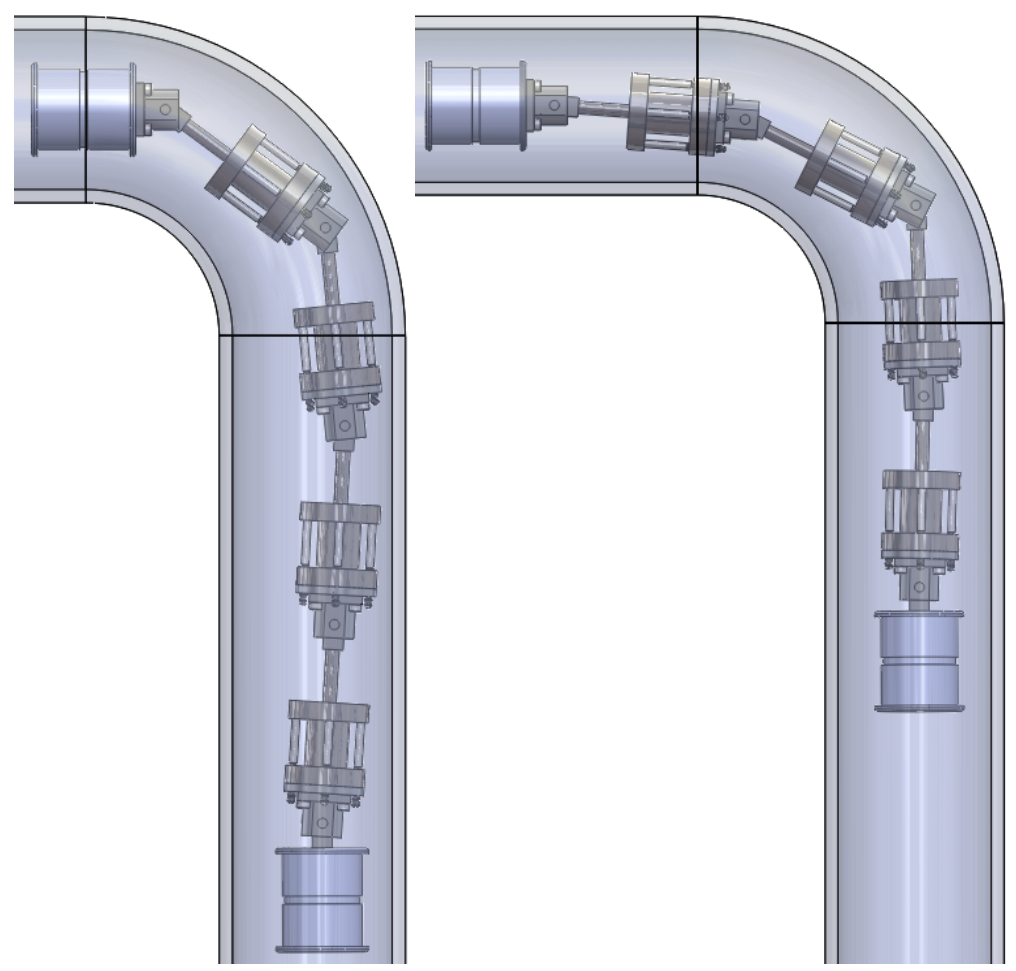

Figure 14: Depiction of Kinematics Through Elbow

\subsection{Valves}

If conventional solenoid valves were used for this device, they would prove to be too large and would have to be mounted outside the pipeline. This was the case with previous versions of the crawler produced by the Applied Research Center [13]. This is not ideal because it creates large delays in the response of the device. Every time a valve is given current, there is a delay between this action and when the air line it feeds becomes fully pressurized. The longer the line, the longer this takes. Once deployed in waste transfer pipes measuring over 100' this would make for a device akin to a MARS Rover, i.e., one which responds to a command a long time after it is sent.

The chart below was obtained by timing how long it took for the body of the third generation device developed by ARC to reach the set pressure over three different lengths of line spanning from 277 " to 554 " and over a range of 10-60 psi. At the 554" inches, 
which are approximately 46', it takes over half a minute to pressurize the bellows to the set pressure of $60 \mathrm{psi}$. Vacuum cycles were found to take even longer.

\begin{tabular}{|c|c|c|c|}
\hline \multirow{2}{*}{} & \multicolumn{3}{|c|}{ Tube Lengths (in) } \\
\cline { 2 - 4 } & 554 & 415.5 & 277 \\
\hline Pressure (lb/in2) & Final Time (s) & Final Time (s) & Final Time (s) \\
\hline 10 & 22.41 & 22.1 & 20.78 \\
\hline 20 & 24.23 & 22.84 & 21.53 \\
\hline 30 & 26.34 & 23.59 & 22.58 \\
\hline 40 & 27.22 & 24.06 & 22.81 \\
\hline 50 & 28.76 & 24.64 & 23.43 \\
\hline 60 & 32.16 & 25.36 & 23.56 \\
\hline
\end{tabular}

Table 7: Time to Reach Set Pressure vs. Tubing Length

This situation was averted on the revised third generation of the device developed by ARC via the use of MAC Bullet Valves ${ }^{\circledR}$. These valves are available in small sizes which allow them to be mounted right behind the crawler. The result is that the lines are always held under pressure and this pressure only enters the crawler when the valves allow for it. Simultaneously, the large time delays are completely eliminated and the crawler responds right when commanded. Due to the fact that this modification was already tested successfully, it was directly implemented in the crawler developed for this thesis. 


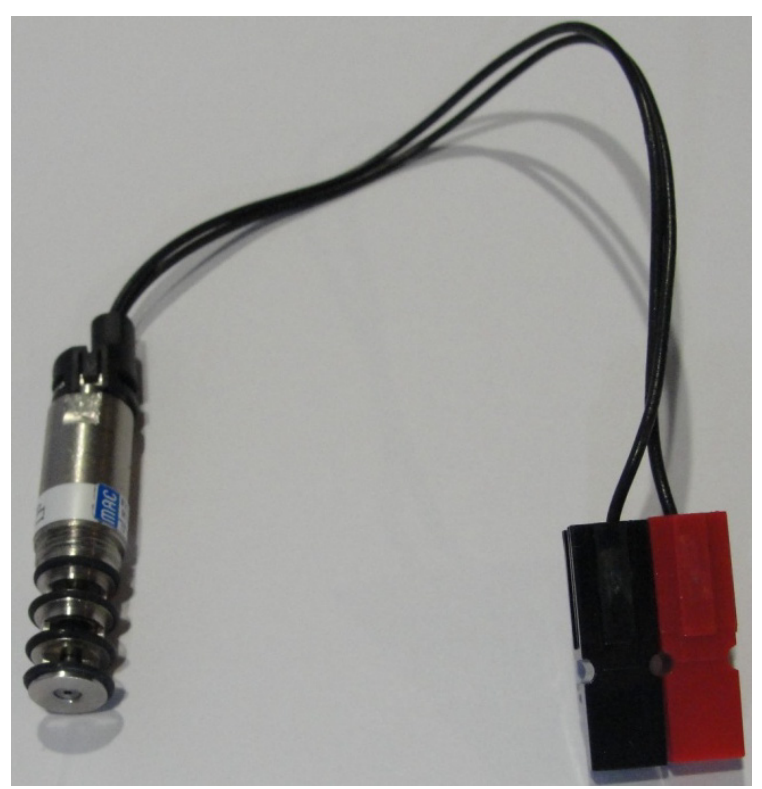

Figure 15: Mac Bullet Valve ${ }^{\circledR}$ with Anderson Powerpole ${ }^{\circledR}$ Connector

These valves do present an extra challenge in that their air channels are tapered and stepped. These dimensions are not standard and it is normally necessary to use the company's proprietary manifolds in order to use the valves. These manifolds are meant for running several valves simultaneously and would not be suitable for this application. However, by taking measurements of the steps with a dial caliper and gauging the thread, it was possible to manufacture manifolds that suited the application. These manifolds are essentially cylindrical sleeves that the valves thread into and they have one side with one threaded port and another side with two threaded ports. Two different designs were made for the manifolds, one design for feeding the crawler's heads and one for feeding its bodies. The main difference is that the manifold design for the bodies has a larger diameter which allows for barb fittings for $1 / 4$ " tube and a 10-32 thread whilst the valves for the head used barbs for $1 / 16$ " tube with a 3-48 thread. 


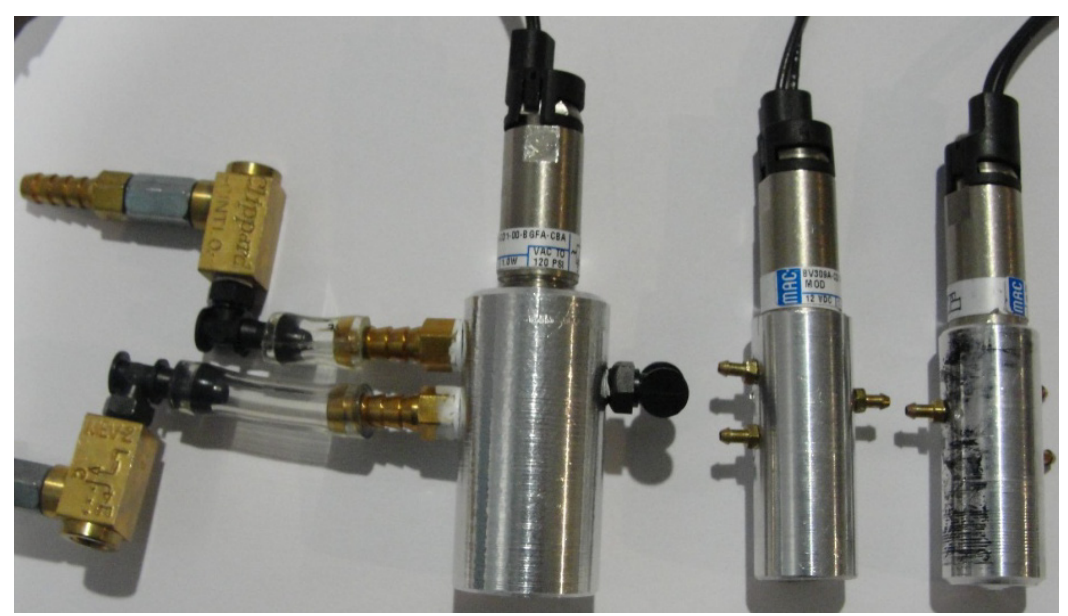

Figure 16: Manifolds for Mac Bullet Valves ${ }^{\circledR}$

It should be noted that these MAC ${ }^{\circledR}$ valves, part number BV309A-CD1, are three way universal valves. Each can provide a $C_{v}$ of 0.06 at 120 psi of inflation [18], making them suitable for feeding all four cylinders with a single valve. In the case of the valves feeding the heads, the sides of the manifolds with two ports receive one air input line and the side with one port is used as an output to the heads. When the valve is given current, the air flows from the input to the output- inflating the bladder on the corresponding head. When current is removed, the valve switches back, allowing the unused port to serve as an exhaust- deflating the bladder. However, in the case of the manifold for the bodies, the side with one port serves as the air input and the side with two ports serves as the output. The port which flows when the valve is not given current is connected to the manifold feeding the retraction ports of the cylinders. As a result, the crawler body remains retracted and if the valve fails, it will fail retracted. The controlled port is connected to the manifold that feeds the expansion ports of the cylinders. When current is sent to the valve, it feeds this port and causes the crawler body to expand. 
This hose routing presents a problem because it does not allow for an air exhaust. As a result, when all the components are sealed properly, the hoses for both the expansion and contraction sides of the cylinders will remain pressurized. These even pressures on either side of the pistons will cause the cylinders to be incapable of expanding and contracting. Initial tests of the system showed that the crawler expanded and contracted, this was due to small air leaks that served as exhausts. Once all components were sealed, the crawler was paralyzed. This was solved via the addition of Clippard MEV-2 quick exhaust valves (QEV). These micro-QEVs are 0.66 " in length, 0.31 " in width and height. Addition of QEVs to double acting cylinders is standard practice in industry and it helps the cylinders to react without any hesitation. Air flow will move an internal poppet forward where it will block an exhaust channel but allow flow around it to the application. Once air flow is cut off, the poppet will move back and allow the pressure in the line to dissipate through the exhaust channel [19].

\subsection{Material Selection}

The crawler prototype built for this thesis is intended for testing purposes only and not for deployment on the actual Hanford site. However, it is ideal to build the robot with as many deployable materials as possible so that it remains close to the final weight. It was decided that $6061 \mathrm{~T} 6$ aluminum would be used for any parts which had to be manufactured. This choice reduced the time and associated cost of machining parts as well as the cost of materials. The heads, adapter flanges, rod eyes, distribution manifolds, and clevis brackets are all made from this material. In the case of the pneumatic cylinders, they are made from 304SS with 6061 aluminum end caps. The fittings used are either brass or high density polyethylene. 
Generally, devices developed at ARC for deployment in Hanford pipelines use 316SS [20]. However, the pipelines and tanks are generally made from steel [15]. The findings of the materials section in the literature survey indicate that aluminum is, in fact, capable of surviving exposure to Hanford levels of radiation. Tanks at Hanford have been measured at $10 \mathrm{~Gy} / \mathrm{hr}$ [15] whereas the damage threshold of aluminum alloys in gamma is $5 \times 10^{11} \mathrm{~Gy} / \mathrm{hr}$ [16]. Aluminum alloys are actually more resistant to radiation than stainless steels [14]. Brass can withstand $1 \times 10^{10} \mathrm{~Gy} / \mathrm{hr}$ before changes in material properties are observed. No number was found for polyethylene; however it is known to have moderate resistance [16] and is listed in Hanford standards document TFC-ENGSTD-34 as an acceptable nonmetal for contact with tank waste [21].

\begin{tabular}{|c|c|c|c|c|}
\hline Vendor & Part\# & Description & Unit & Cost per \\
\hline McMaster & $8974 K 711$ & 6061 Aluminum rod 2" O.D., 12" Iong & ea & 59.97 \\
\hline McMaster & $8974 K 181$ & 6061 Aluminum rod 1.5" O.D., 12" Iong & ea & 35.13 \\
\hline
\end{tabular}

Table 8: Raw Materials

\subsection{Tooling}

The tooling used for the manufacturing part of this thesis was generally made of high speed steel (HSS). HSS tooling is cost effective and can be used to cut stainless steel as well as aluminum [22]. Carbide tools are available at a higher cost but they can be run at higher rpm and surface speeds than HSS. However, for the 6061 aluminum used here, HSS can cut at a desirable rate without the cost penalty of carbide [22]. The one exception was the cutter used for turning operations which has a C6 carbide tip. In this instance, since only a simple tip is made from carbide, the cost was $\$ 4.85$ and was not prohibitive. Also, the removal rates used with this tool were calculated under the assumptions of a HSS tool. The various tools used are shown below: 


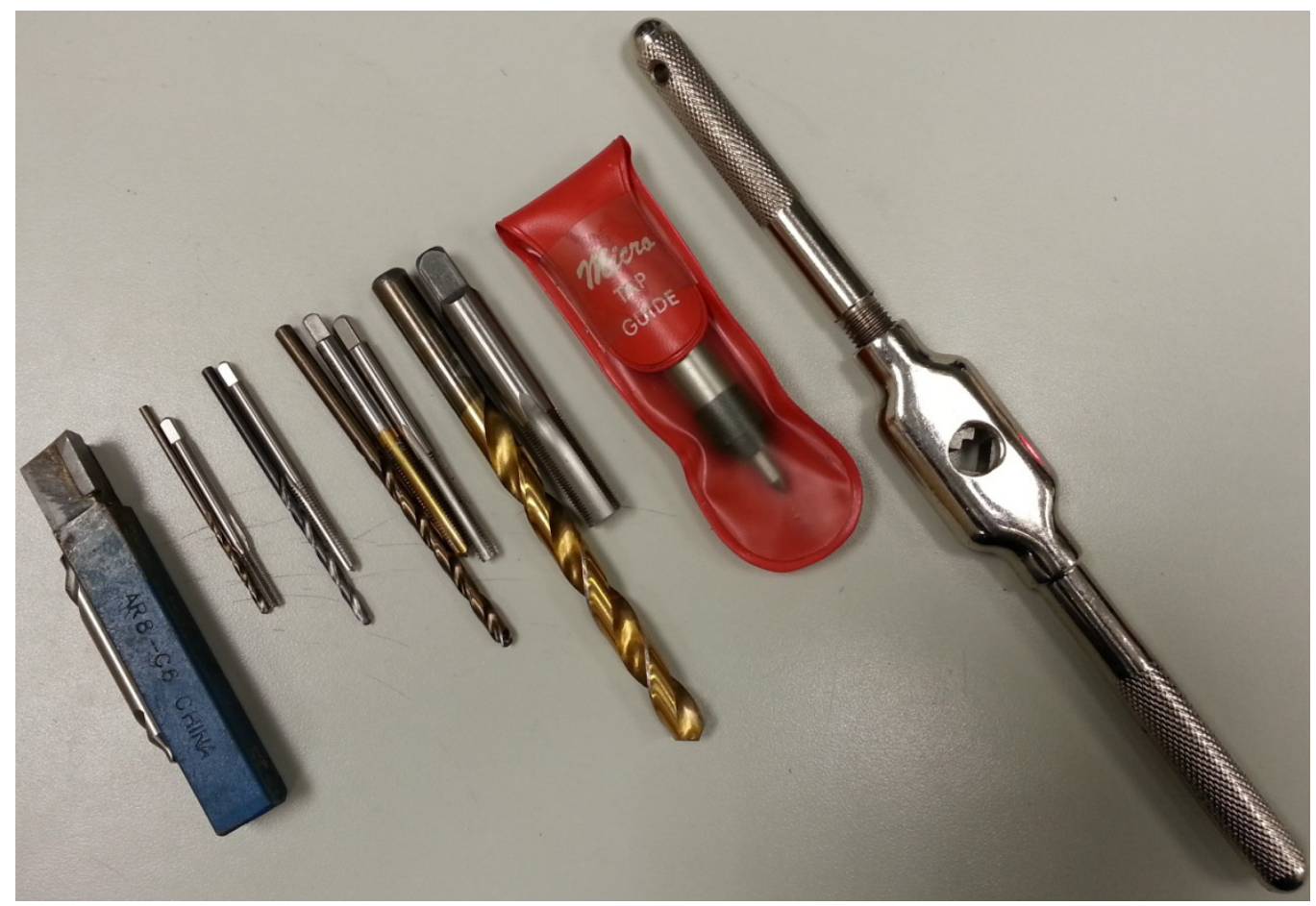

Figure 17: Tooling

Pictured from left: No3 starting bit, C6 right hand lathe cutter, \#47 drill bit and 348 tap, \#36 drill bit and 6-32 tap, and \#21 drill bit and 10-32 starting and bottoming taps, 9.25mm drill bit and M10x0.75 tap, tap guide, and tap wrench. 1/2" end mill not shown.

\subsection{Manufacturing Processes}

Each flange was machined from 1.5" OD 6061 T6 aluminum rod by facing off an end on the lathe and then cutting the faced off disk on a horizontal band saw. The process would then be repeated in order to create the next flange disk. The flanges were then clamped in the jaws of a milling machine with the band saw cut facing up. This side was then milled down, bringing the disk to the desired thickness. From here, holes were marked and drilled with a \#36 bit on a drill press, followed by tapping them to a 6-32 thread. 


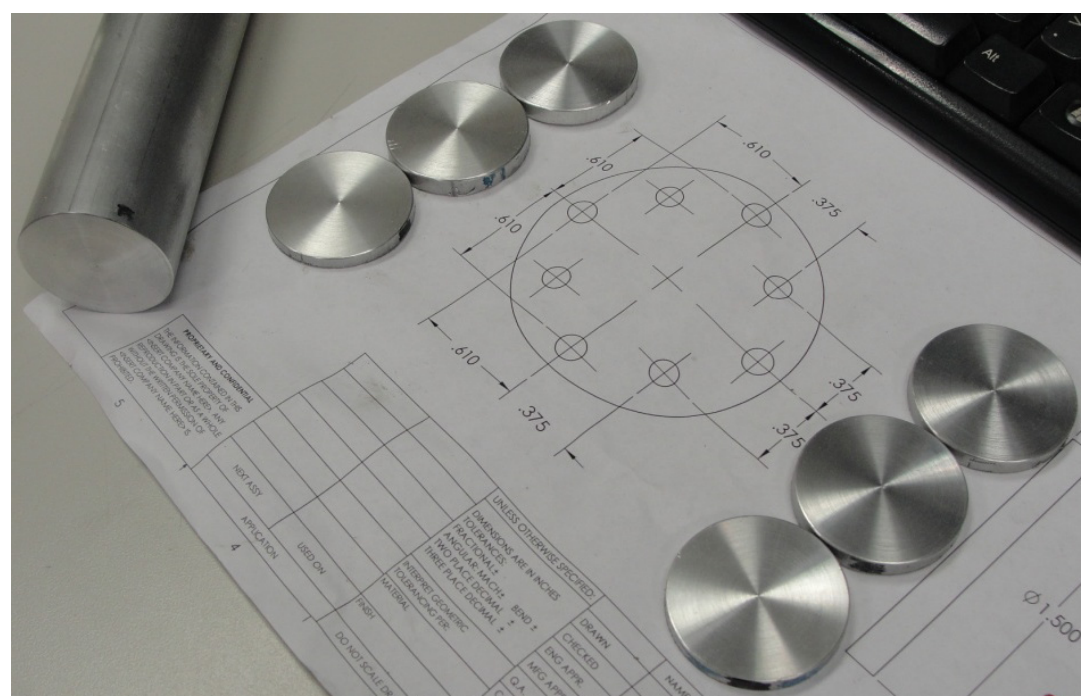

Figure 18: Freshly Turned Adapter Flanges

The heads on either end of the crawler were made by turning 2" OD 6061 T6 aluminum stock on a lathe. The lathe was used in order to produce the external features of the heads and in order to mark where they were to be cut off from the stock. Each head was then parted from the stock and the drill locations for its holes were marked. The holes were drilled by clamping the heads in a vice and drilling with a drill press. The holes used for fittings and for mounting bolts were then tapped. For simplicity and uniformity, all fittings on the crawler and rod connections use a 10-32 threading and mounting bolts use a 6-32 threading. The clevis bracket that the front head attaches to was notched with an end mill such that it would not interfere with the front air fitting. 


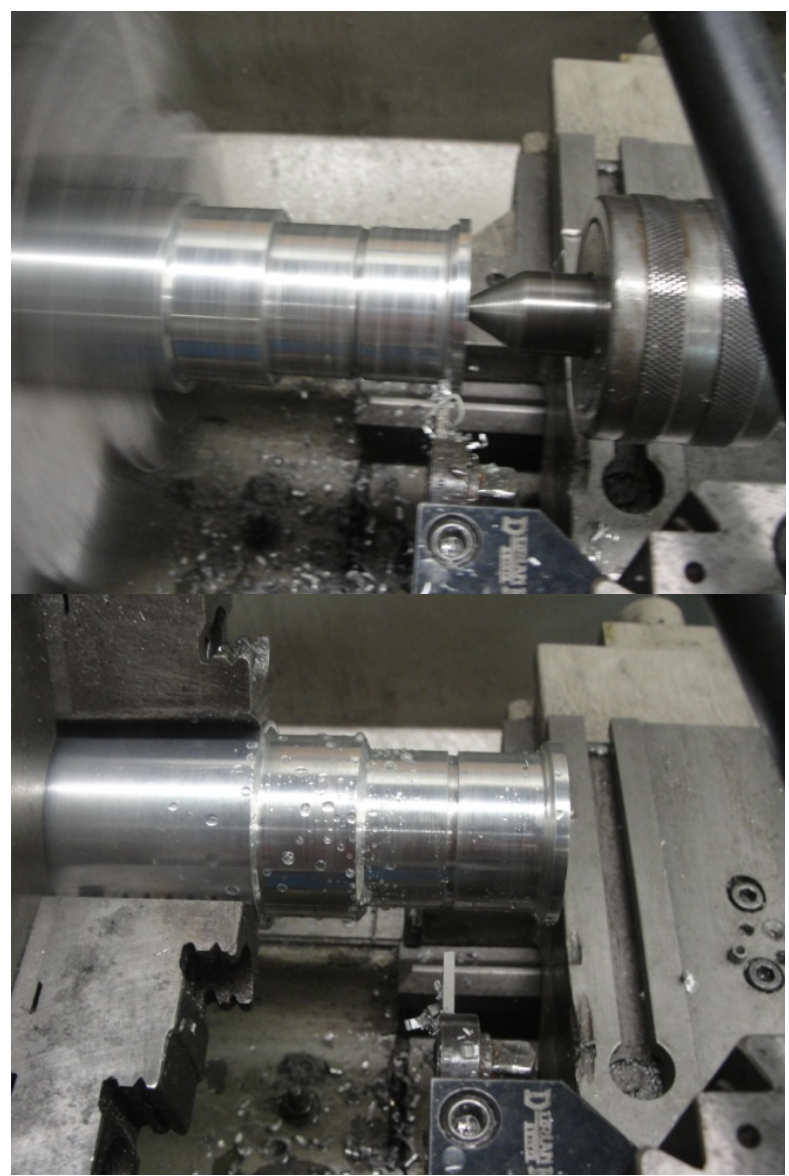

Figure 19: Turning Crawler Head on Lathe

In order to be able to feed all four cylinders with one valve, it is necessary to use distribution manifolds. There are two manifolds in the system, one for expansion and one for contraction. Each has one input consisting of a barb fitting for $1 / 4$ " tube and four outputs consisting of barb fittings for $1 / 16$ " tube. Their bodies were made by turning a 1/2" rod of 6061 T6 aluminum down to $3 / 8$ " on the lathe and boring it up to a \#21 drill bit. This rod was milled flat on opposite sides of the circumference and then sectioned into two cylinders, each 1.25 " in length. Ports were drilled on the milled faces up to a \#21 drill bit, one side with one port and one side with four for each manifold. These ports were all tapped to a 10-32 thread. The same was done on either end of each cylinder in 
order to close off the axial bores using screws and thread sealant. The appropriate fittings were then added, completing the process.

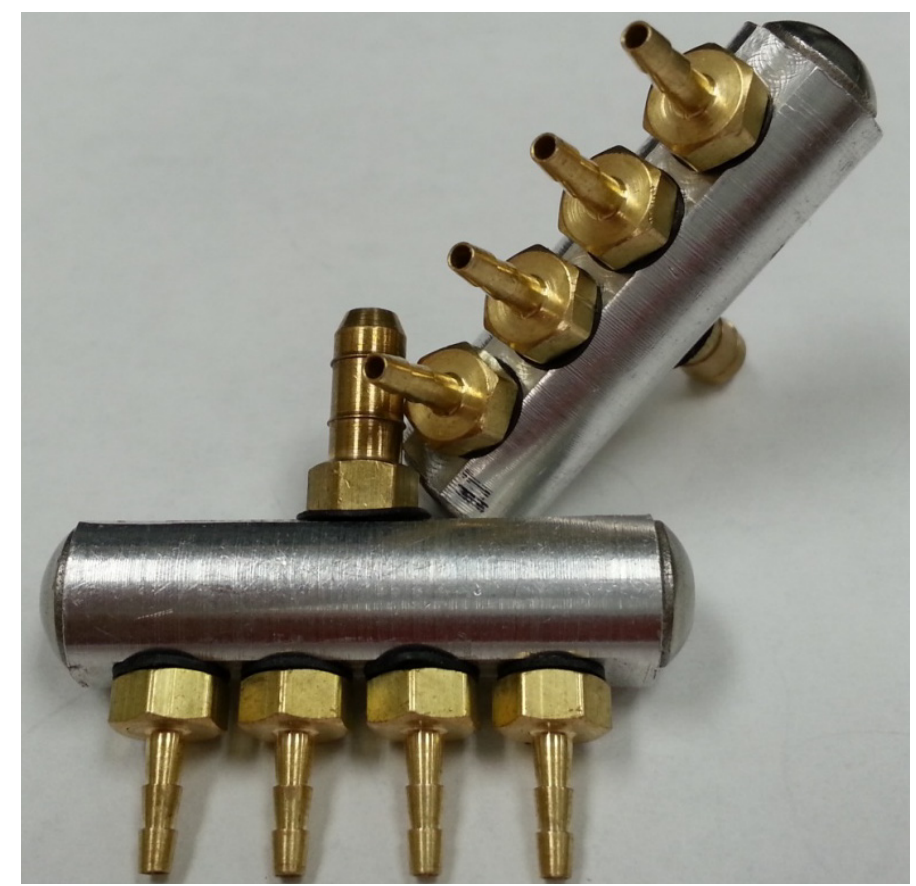

Figure 20: Completed Distribution Manifolds

\subsection{Assembly}

Each rod eye has a 10-32 male threaded end that threads into a female end on each piston rod in the cylinders. These rod eyes have an opening through which a pin passes. This pin is in turn attached to a clevis bracket via two holes and a retaining clip on either end. Four stainless 6-32 bolts pass through the openings on the flat end of each clevis bracket and into a flange. Through the opposite side of the flange pass another set of 6-32 bolts which attach each flange to the back of a cylinder. This method is used in order to array four cylinders into one crawler body. The rear head is attached to the rear most rod eye via a 10-32 threaded female end. The front head attaches to the front clevis bracket via four 6-32 bolts. This clevis bracket is also modified with a notch in order to accommodate the front air fitting. 
Ten fittings are used for the crawler, eight for the cylinders and two for the heads. The eight fittings on the cylinders are $90^{\circ}$ barb fittings with a 10-32 thread and a barb for 1/16" tube. The fittings on the heads are straight fittings, also with a 10-32 thread and a barb for $1 / 16 "$ tube.

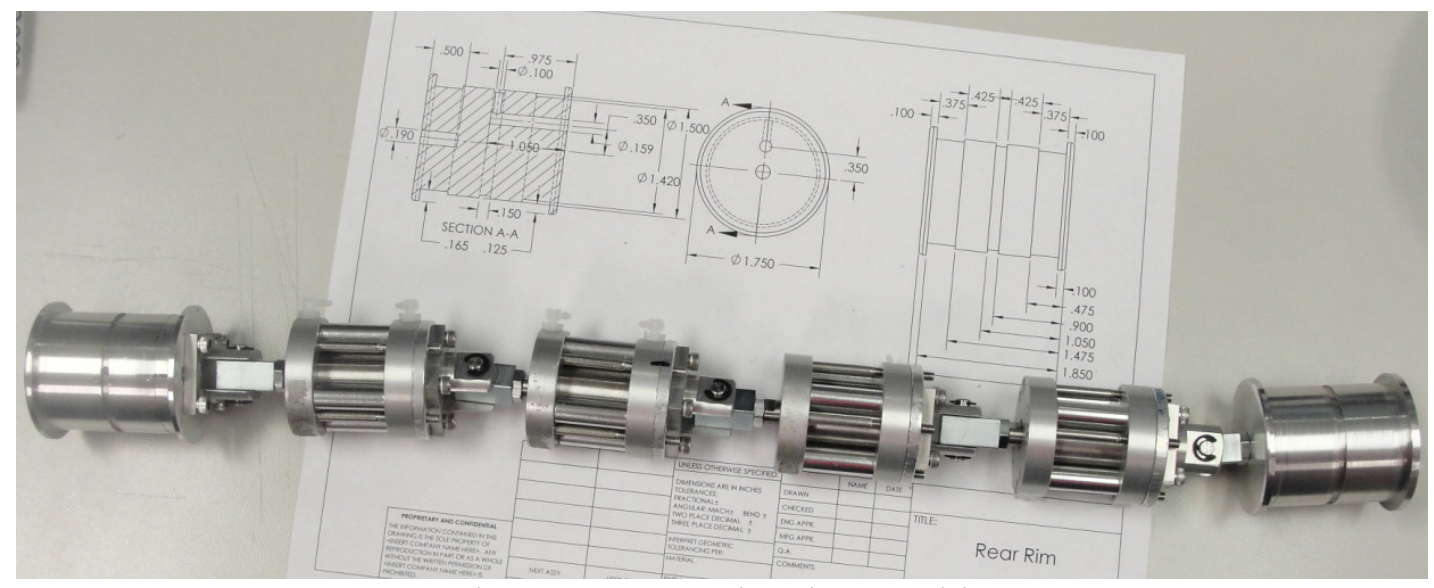

Figure 21: Completed Assembly 


\section{Control Setup}

\subsection{Controller Box}

A control box was built in order to facilitate operation of the crawler. The box provides the ability to move the crawler forward or backward by using a joystick, or simply turning on a switch- one for forward motion and one for reverse. These functions are executed by an Omron Zen Programmable Logic Controller (PLC). The controller is programmed to send current to the valves in sequence and for a specific amount of time in order to generate the crawler's motion. The control box also includes switches which bypass the PLC, sending current directly to each valve, allowing for independent control of the crawler's bodies.

\subsubsection{Omron}

The Omron Zen PLC serves as the brain of the control box for the crawler. The top portion of the device consists of inputs. There are inputs $\mathrm{L}$ and $\mathrm{N}$ which are for line and neutral respectively, these provide AC current to the Omron. The other inputs are numbered from I0 to I5 and are programming inputs. When current is received by any of these inputs, it triggers the program which corresponds to it. This means that a total of six programs may be stored on the Omron and this is useful for having the crawler adapt to various situations. It may be desirable to have different programs to control each of the

crawler's possible motions, these being forward through straight sections, forward through elbows, reverse through straight sections, and reverse through elbows. Also, if more valves are added, programs can be written for cycling the cylinders in phases in order to create different styles of motion. 
The device has four outputs which are labeled from Q0 to Q3. Each one of these outputs is actually a relay and sending current through any of them is how the Omron executes its control functions. By sending current in sequence to these relays, for a given amount of time per relay, the valves feeding the crawler can be controlled in order to create any of its motions.

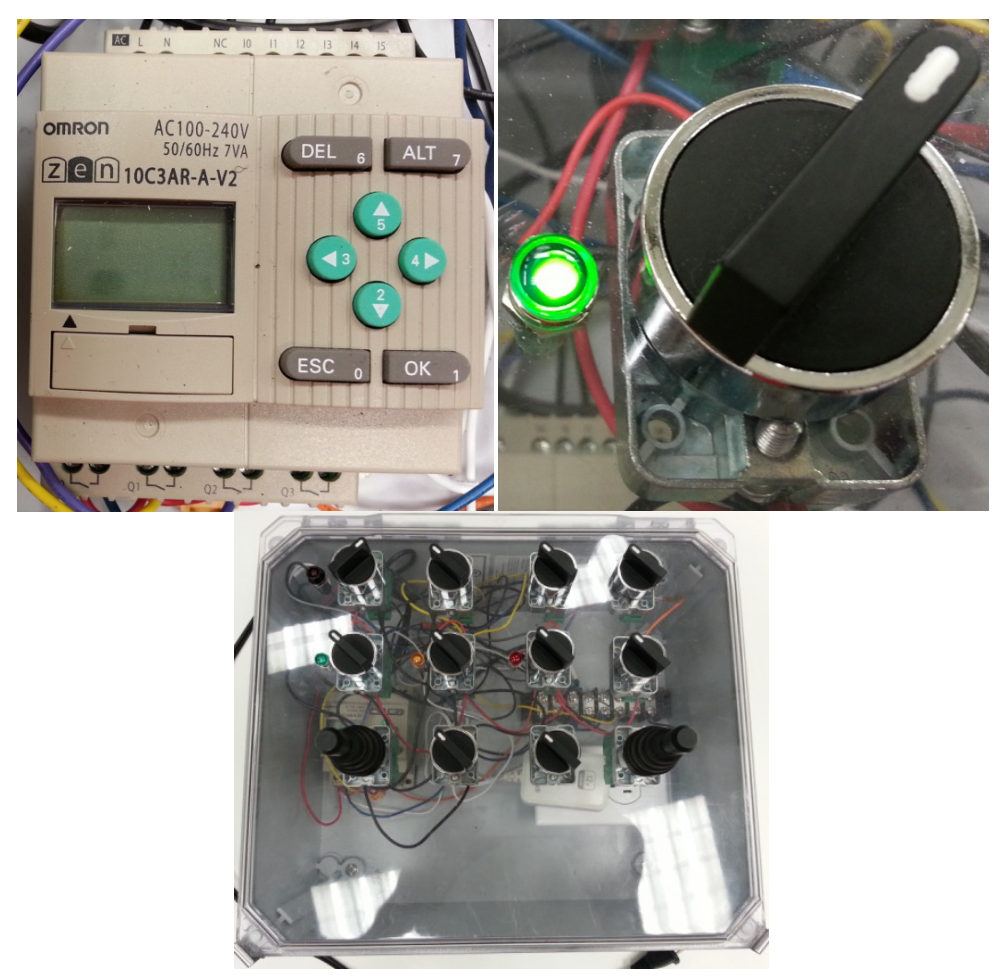

Figure 22: Control Box Setup 


\subsubsection{Wiring}

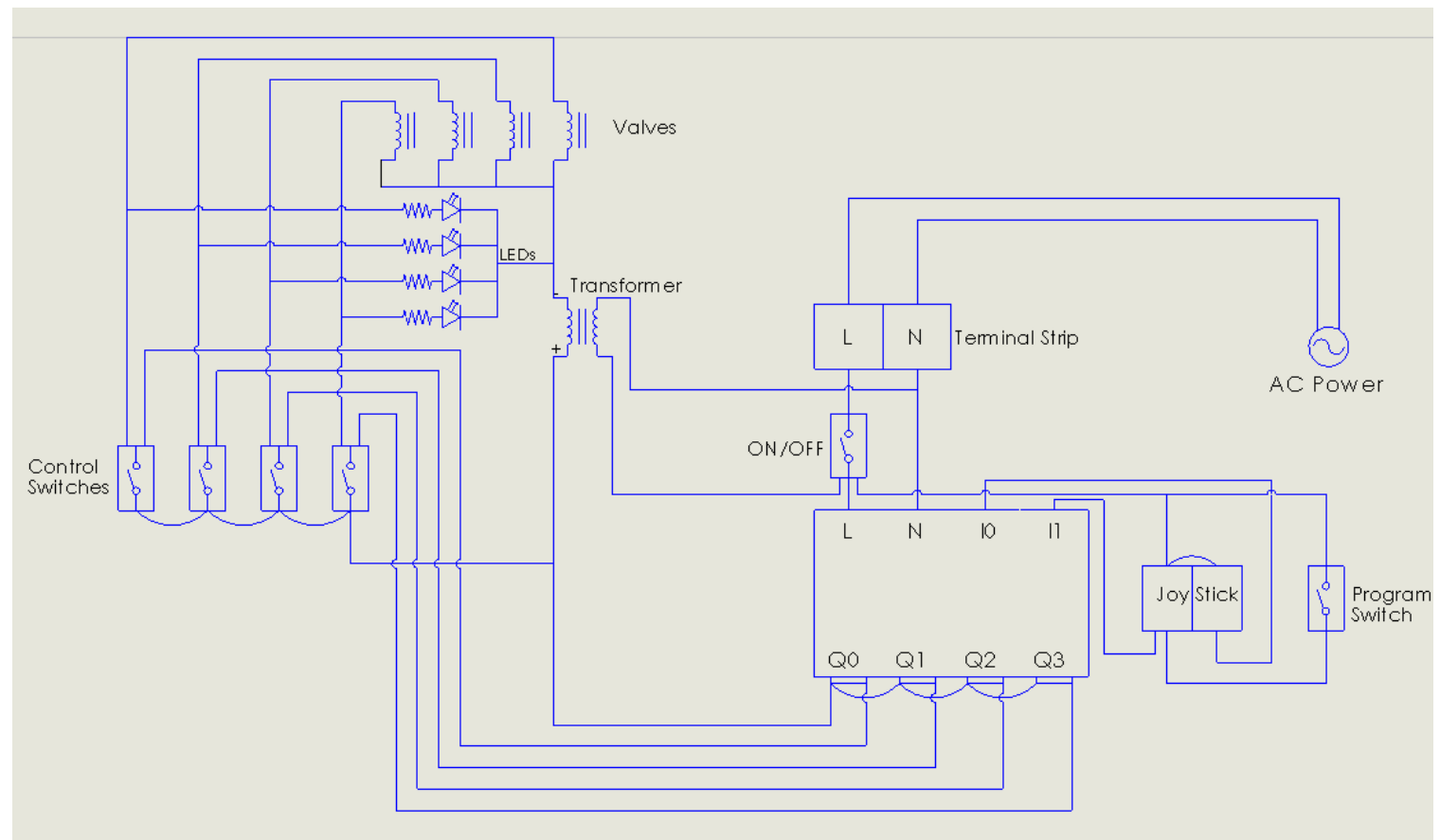

Figure 23: Control Box Wiring Diagram

In order for the operator to control the functions of the PLC and thus, the crawler robot, switches are needed to trigger its functions. All of the components for making this possible are contained within a sealed box. Current comes into the box from a conventional 110VAC wall outlet via a two strand power chord. Both strands are bolted down on a junction block, allowing for multiple components to take current from them if needed. A wire is fed directly from the neutral slot on the PLC to the neutral slot on the block whilst the wire from the PLC to the line slot is interrupted by a switch. This switch serves as the ON/OFF switch for the system. An AC powered LED is connected to the line after the switch and the neutral slot on the junction block in order to indicate when the system is on. Line and neutral are also fed off the junction block toward an electrical outlet housed within an Underwriters Laboratory industrial enclosure. A $12 \mathrm{~V} 500 \mathrm{~mA}$ AC 
to DC transformer is plugged into the outlet. Each valve consumes approximately 83.3mA under operation, so the transformer provides enough current to run up to six valves. Over longer lengths of wire, the voltage drop would require a more powerful transformer, however for the $25 \mathrm{ft}$. test setup, this transformer sufficed.

The positive strand from the transformer is fed into the left slot on the Q0 relay on the PLC. From here it is bridged into the left slots on relays Q1, Q2, and Q3. From there, a wire is sent from the right slot on each relay to the top of one of four switches and from there to one strand of each respective DC solenoid valve. The second strand of each valve is in turn connected to the negative strand of the transformer, thereby completing the circuit. This allows for the PLC to send current to each valve as needed via the program written into it. At the same time, the bottom of each of the switches is connected to the positive strand on the transformer such that the switches may be used to send positive current to the DC solenoid valves independent of the PLC. This allows for manual override control of each valve. An LED is connected from the positive to the negative strand of each DC valve. These serve as indicators that power is being sent to a valve and allow for the program sequence to be observed without the robot connected.

In order to trigger the program sequences in the PLC, both a switch and a joy stick are used. The switch receives line from the ON/OFF switch and feeds back into the I1 slot of the PLC. When this switch is closed and current flows to I1, it executes the program stored under I1. One pole of the joystick is also fed line and run into the I1 slot so the I1 program can be executed for as long as the joy stick is pushed forward. The line is also bridged to the opposite pole of the joy stick and from there it feeds into the I0 slot 
on the PLC. This allows for the I0 program to be executed when the joy stick is pushed backward. No current flows when the joy stick is at rest in the center position.

These simple means are used in order to create a sealed control box that contains all of the electronics and current needed to operate the crawler robot. The simple internal conversion from AC to DC current allows for the use of DC valves, however, the setup can be converted to operate AC valves by simply eliminating the transformer and sending line into the relays in place of positive current. The remainder of the circuit does not need to be modified in any way.

\subsection{Pneumatic System}

\subsubsection{Source}

The source used for providing the crawler setup with air is a conventional air compressor. This source cannot provide more than 100 psi of pressure; therefore any values of the crawler's performance above these pressures must be extrapolated from data taken at lower pressures. Alternatively, testing can be done at an auto shop which uses a larger compressor, body shops are ideal. It is possible to connect a compressor to the setup via a female quick-release coupling. A device capable of providing up to 250 psi would be ideal in the field as this would allow for the full potential of the cylinders to be used.

\subsubsection{Distribution}

The air from the source is fed into a manifold with several outputs. Each output has its own regulator, allowing the output pressure at that point to be controlled. This is important mainly because the pneumatic cylinders of the crawler and the bladders on its heads are kept at different pressures. This also allows for the pressure to be varied as the 
robot is in motion in order to adapt to changing conditions in the pipe. These changes are left at the discretion of the operator.

\subsubsection{Umbilical}

For the purposes of the tests conducted for this thesis, the umbilical for the crawler consists of a $25^{\prime}$ line. This line is comprised of a cable with eight conductors in it and three $1 / 4$ " tubes which are attached to each other. The cable has Anderson Powerpole ${ }^{\circledR}$ connectors at either end, and only six of the eight conductors are used. On the end that goes to the crawler, there are three pairs of connectors, each pair consisting of one positive and one negative. These plug into Anderson ${ }^{\circledR}$ connectors on the valves, allowing for any damaged valves to be quickly disconnected and replaced. On the end that goes to the control box, the three positive strands each have their own connector whereas the three negative strands are crimped into a single connector. The Anderson ${ }^{\circledR}$ connectors are attached to each other via built in grooves, forming one large connector that plugs into a matching one on the box. This connector in turn, is wired to the terminal strip and receives current inputs from each one of the control outputs from the PLC. Standard DC current color conventions are followed, thus all positive strands have a red connector whilst all negatives have a black connector.

The hoses are connected to the distribution manifold on one end and connected to the robot's valves on the other. On the manifold side, this is accomplished by the use of barbed fittings. On the side of the valves, barbed fittings are used again as each valve has its own manifold and input/output fittings. Two of the hoses have reducing fittings that drop the size down from the $1 / 4$ " tube to $1 / 16^{\prime}$ I.D. tube so that they can fit the barbs on the smaller valve manifolds used to feed the heads of the crawler. The $1 / 4$ " tube is 
acceptable for these purposes as it does not create too large of a diameter in the umbilical and also because flow rate is not an issue. Thanks to the valves being mounted right behind the crawler, the lines are always pressurized. Thus the only requirement is that they provide enough air volume to feed the crawler. This is accomplished thanks to the large $\mathrm{C}_{\mathrm{v}}$ of the valves. The following is a diagram of the ideal pneumatic system for the crawler:

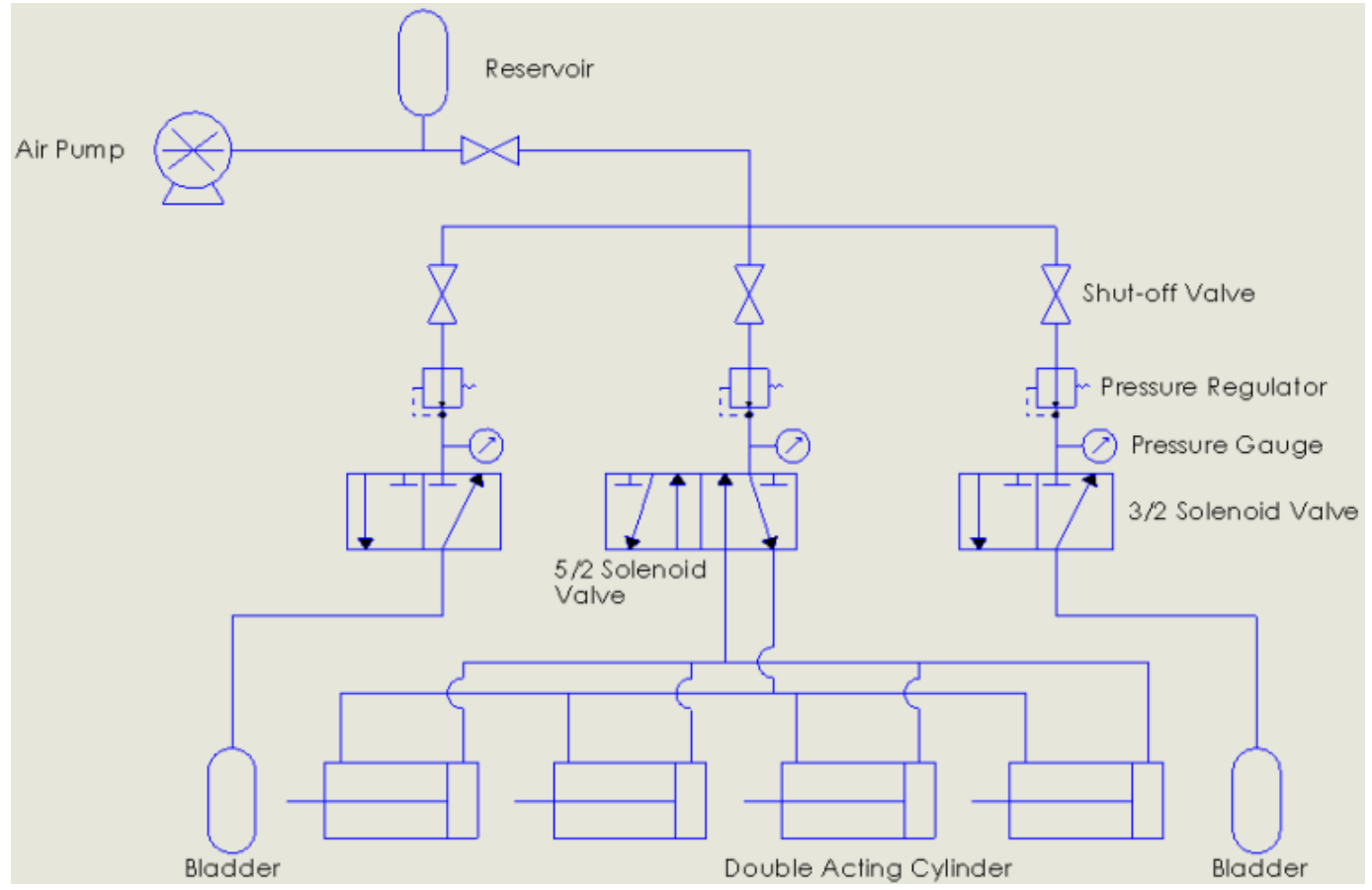

Figure 24: Pneumatic Diagram

In this configuration, a $5 / 2$ solenoid valve would be used to feed the cylinders of the crawler's body. This would allow for feeding either side of the cylinders with air pressure whilst the opposite side is allowed to exhaust [23]. In the configuration actually tested, the available $3 / 2$ valve was installed such that it has one input and two outputs and exhaust duties are left to the quick exhaust valves. 


\subsection{Programming}

\subsubsection{Language}

The Omron Zen can be programmed using the Zen Support Software. This program uses a ladder style programming approach [24] which is appropriate for operating a PLC. The basic logic is that a circuit of the relays is built in the program and time steps are given to each relay during which the relay will provide current to its respective output. When timed properly, this creates a program which will actuate the valves correctly and move the crawler in the desired way.

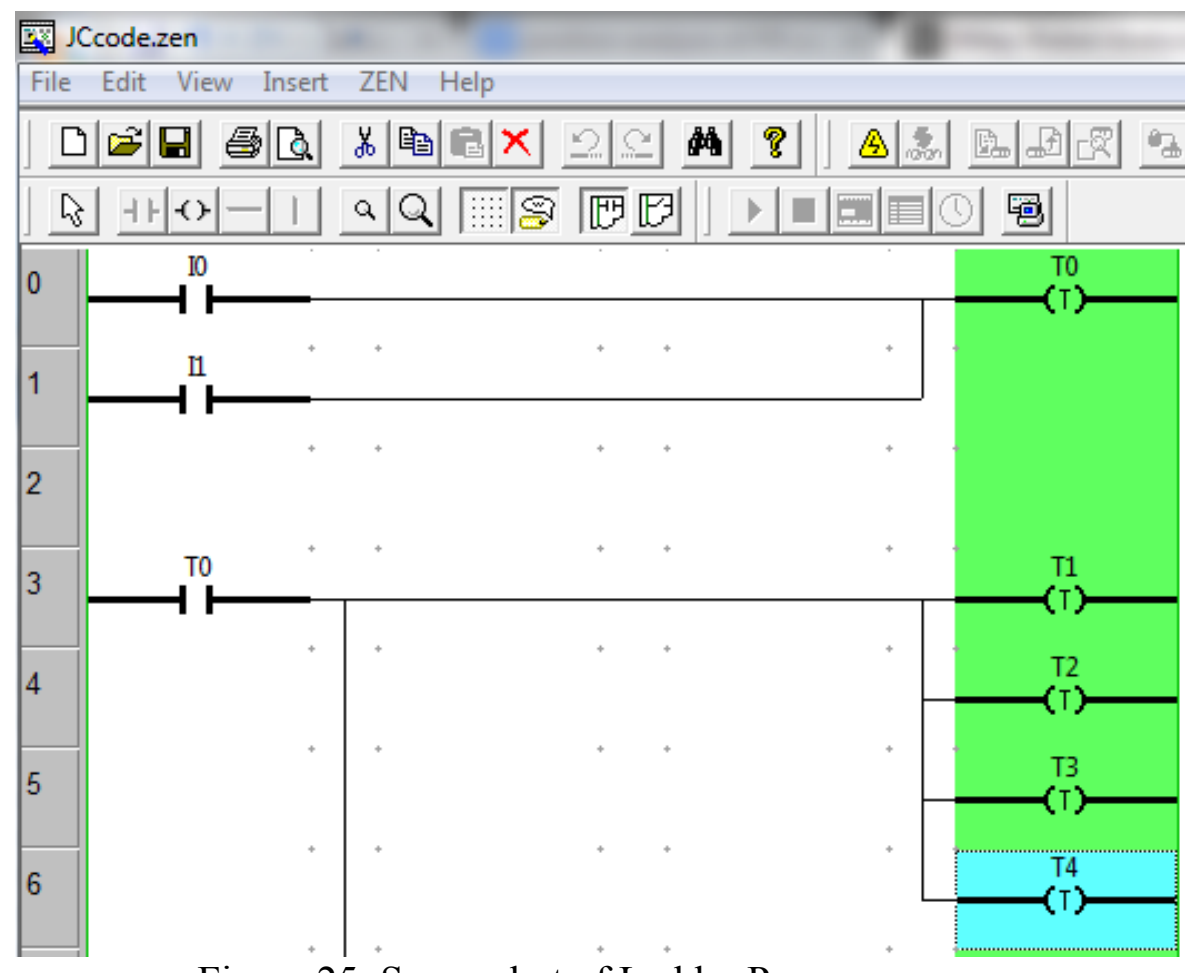

Figure 25: Screenshot of Ladder Program

\subsubsection{Approach}

Properly controlling a crawler involves writing a baseline program and then optimizing it by testing. The parameters for the baseline program were obtained by using the manual control switches to expand each of the cavities in sequence. The time each 
body takes to expand was measured with a stop watch and the overall cycle time was also measured. These numbers were then used to set the times for the program. With this written, the crawler was allowed to move down the pipe and timed. The behavior of the device was observed carefully and modifications were made to the time steps based upon this. The general approach is to modify the time steps such that the crawler can cycle within the shortest possible time while not suffering from slippage. 


\section{Testing}

\subsection{Speed}

\subsubsection{Test Setup}

Verifying the approximate speed of the crawler in a straight pipe is a simple matter. All that is needed is a section of clear 3" I.D. PVC pipe. The straight section used for verifying baseline speeds in a 3" I.D. pipe was actually part of a basic test bed consisting of a 43 " long, 3" I.D. pipe, a 4.25" radius elbow, and 25.25" long, 3" I.D. pipe. In order to gauge the speed of the crawler, the initial position of the front head is marked and the crawler is allowed to cycle forth while a stop watch runs. The crawler and stop watch are stopped simultaneously right when the crawler is ending an expansion stroke and the front rim has anchored. The position of the head is then marked. The distance from beginning to end is then measured and with this and the elapsed time, velocity may be calculated by dividing the displacement by the time. In this case, the displacement and time were in inches and seconds respectively. These results were multiplied by $\frac{3600}{12}$ in order to convert to $\mathrm{ft} / \mathrm{hr}$.

The speed of the crawler through an elbow is a different matter. Using the basic test bed from the 3" I.D. speed test, the crawler is cycled until the front head is lined up with the entrance to the elbow. The crawler is cycled forth while a stop watch runs and they are both stopped simultaneously when the back face of the rear head has exited the elbow.

\subsubsection{Results}

It was necessary to run a speed test by operating the crawler manually in order to time the cycles and tailor a program to operate it. Once a program is written, further 
testing may be done and cycle times may be optimized. The results of the manually controlled tests are shown in the figure below. For linear speed, three trials were completed, allowing the crawler to travel 15-16 in per trial. Each successive run provided a faster time as operator error decreased and more efficient ways of cycling the crawler were realized. The fastest time achieved was $176 \mathrm{ft} . / \mathrm{hr}$. For cornering speed, the crawler was cycled through a regulation Hanford elbow for three trials. The fastest time through the elbow was $14.17 \mathrm{ft} . / \mathrm{hr}$. which amounts to clearing an elbow within 1:30. It was found that these times were achieved with air leaks at the manifolds. This realization led to the manifolds being sealed fully, and was followed by the installation of quick exhaust valves.

\begin{tabular}{|c|c|c|}
\hline \multicolumn{3}{|c|}{ Linear Speed } \\
\hline Distance (in) & Time (s) & Speed (ft/hr) \\
\hline 15.06 & 47.7 & 94.81 \\
\hline 15.63 & 32.9 & 142.3 \\
\hline 16.00 & 27.2 & 176.73 \\
\hline
\end{tabular}

\begin{tabular}{|c|c|c|}
\hline \multicolumn{3}{|c|}{ Cornering Speed } \\
\hline Distance(in) & Time(s) & Speed (ft/hr) \\
\hline 4.25 & 101.00 & 12.62 \\
\hline 4.25 & 93.00 & 13.71 \\
\hline 4.25 & 90.00 & 14.17 \\
\hline
\end{tabular}

Table 9:Baseline Linear and Cornering Velocities

Using these results as a guideline, a program was written to control the crawler. Also, it was noticed that the front head ended up angled out of position when coming out of the elbow. This was due to the bladder material not expanding enough and allowing the head to turn more than desired. This was corrected by using another bladder tube. A test with the program was then carried out. For this portion of the testing, an $8 \mathrm{ft}$ section of clear, 3" PVC was sourced and used as a test bed. A starting position for the front of the robot was marked for the purpose of maintaining a constant travel distance. It was marked such that the front is allowed to travel 75.5." The tests were then conducted again 
with the program modified in order to achieve improvements in the speed. Below are the results of the first run of the device with the program:

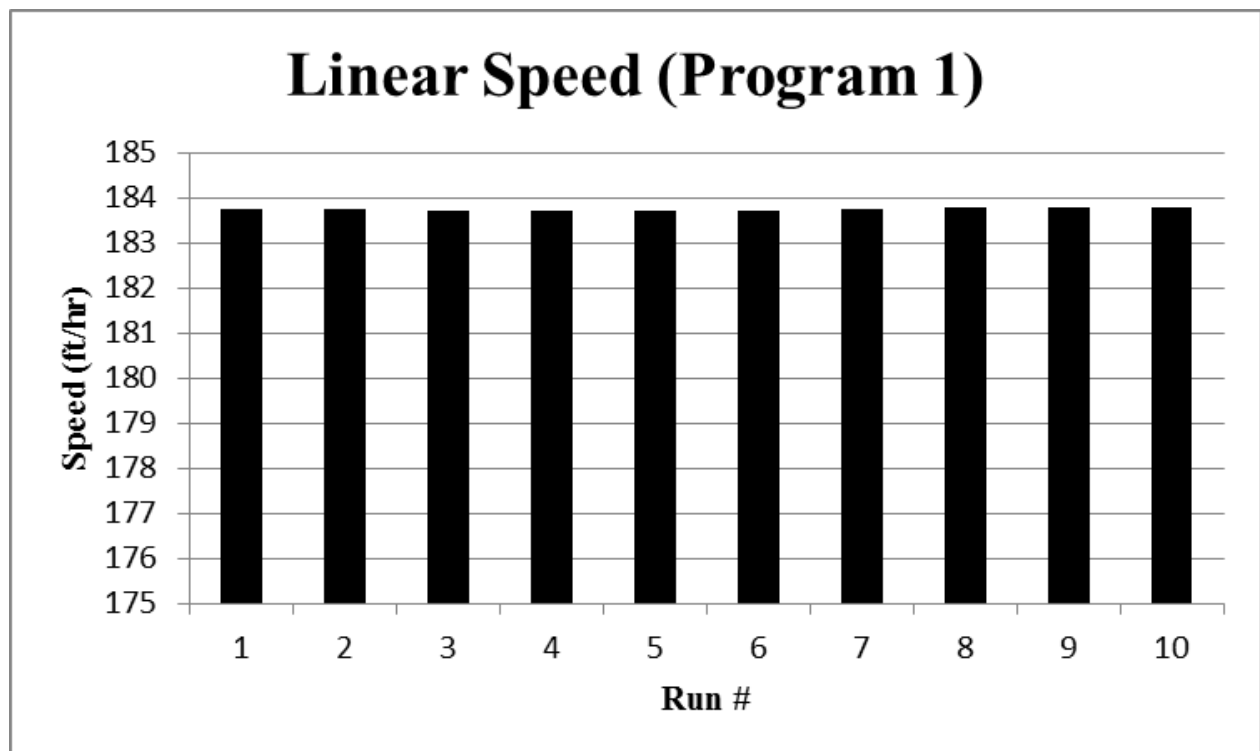

Figure 26: Linear Speed Results with PLC Program 1

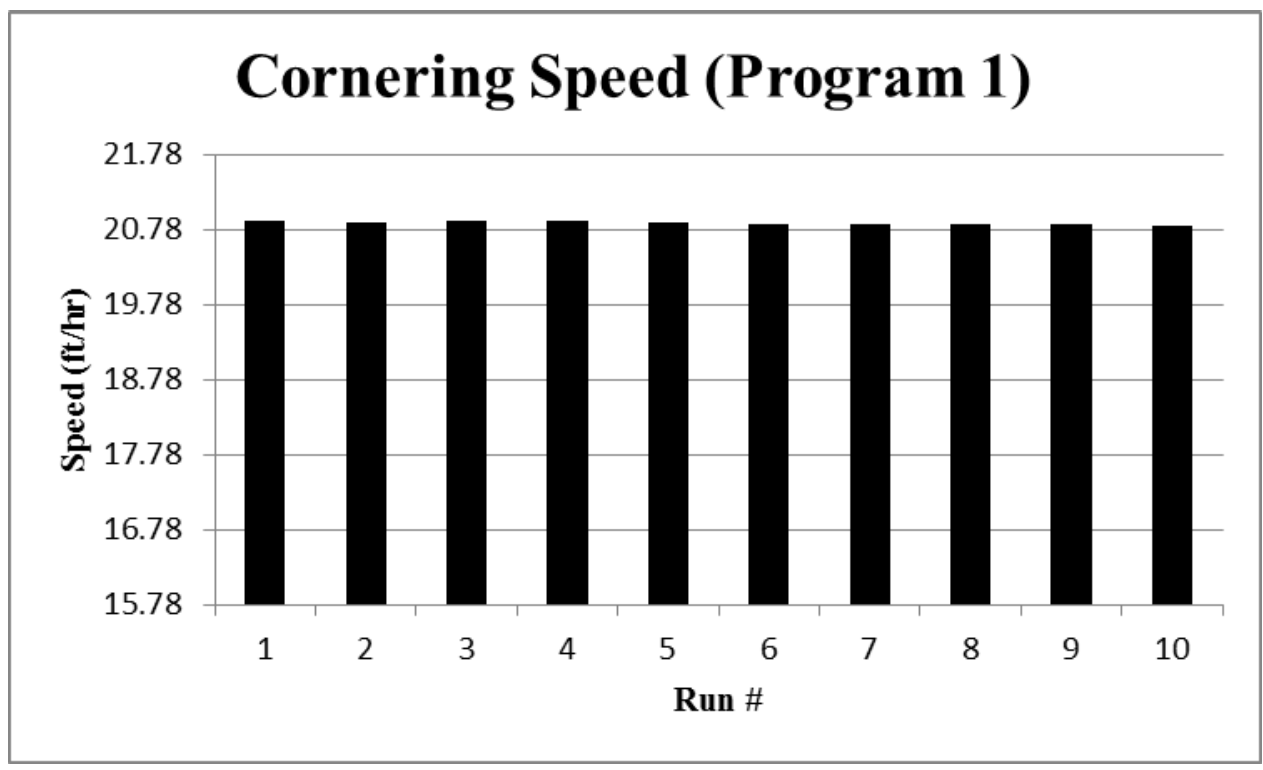

Figure 27: Cornering Speed Results with PLC Program 1

The average linear speed was $183.7 \mathrm{ft} / \mathrm{hr}$. This was complemented by a $20.86 \mathrm{ft} / \mathrm{hr}$ speed in the elbow, which translates to clearing the elbow in just over a minute. These times were shorter than what was previously achieved; however there was room for 
improvement. Modifications were made to the program in order to reduce overlap time between inflation of the front and rear bladders. Once the program was modified, the following results were obtained:

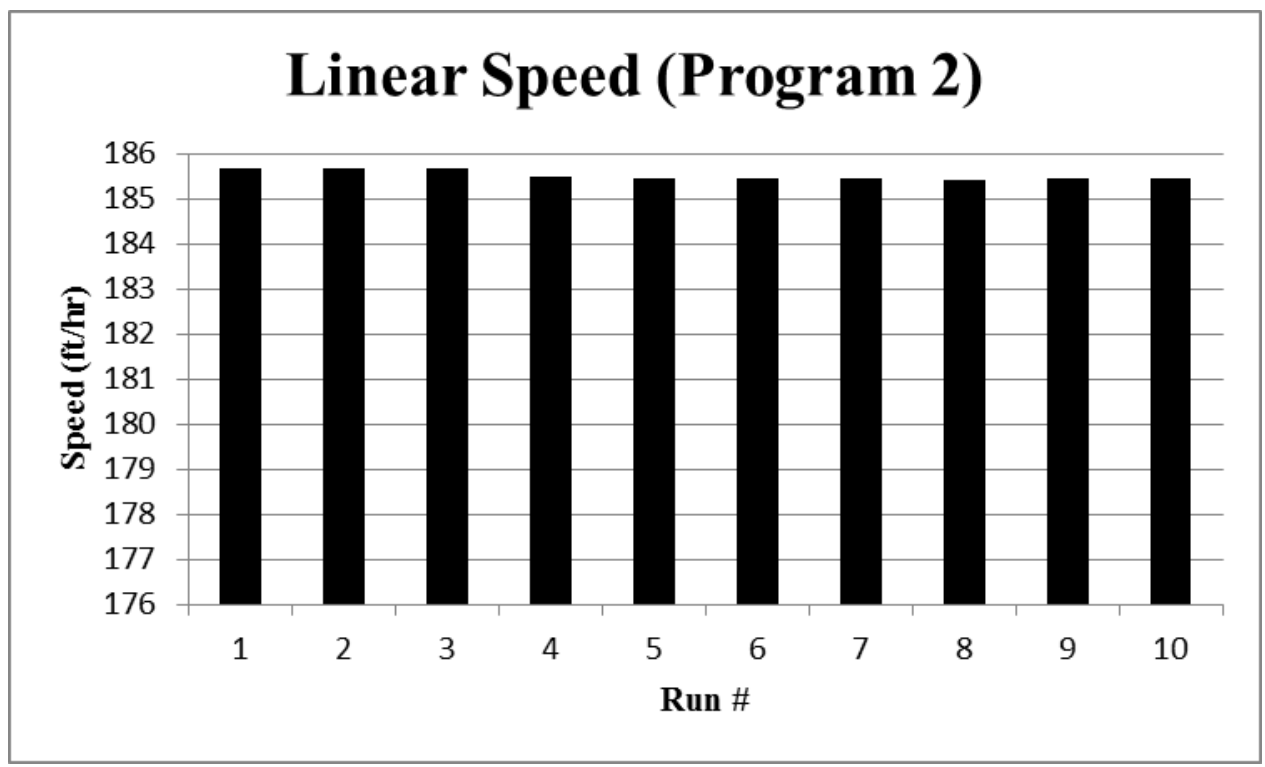

Figure 28: Linear Speed Results with PLC Program 2

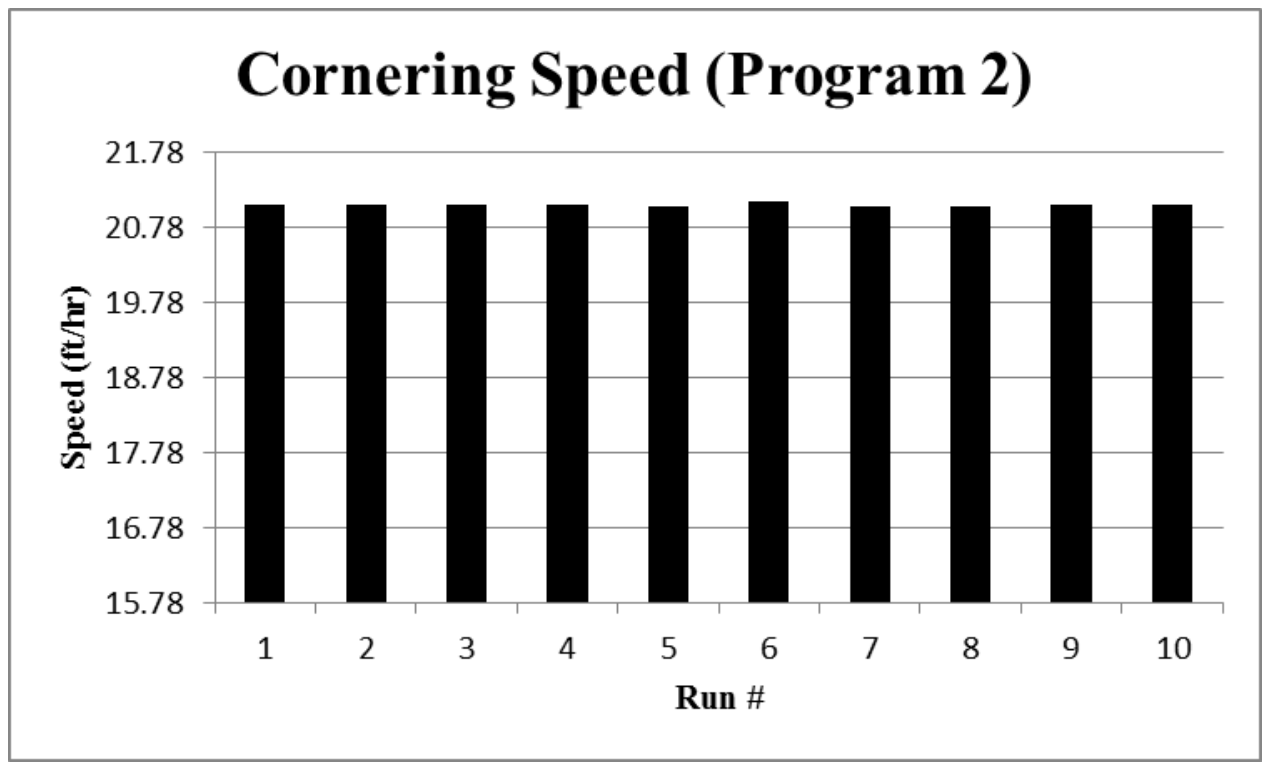

Figure 29: Cornering Speed Results with PLC Program 2 
The program modifications led to noticeable increases in speed. The time to perform the linear cycle was shortened approximately 1.2 seconds, leading to a speed increase of around $1.8 \mathrm{ft} / \mathrm{hr}$. The time to traverse an elbow was reduced approximately 0.6 seconds, leading to a speed increase of around $0.2 \mathrm{ft} / \mathrm{hr}$. These increases in speed can add up to considerable time savings over the course of an extended pipeline. It should be noted that the limiting factor for the overall speed is the time needed to inflate the bladders. If this system were replaced in the future with a more efficient mechanism, the crawler could potentially complete a full expansion and contraction cycle in 2 seconds. This would translate to a speed of $600 \mathrm{ft} / \mathrm{hr}$, drastically shortening unplugging schedules. As there are countless ways to approach a better head design, and because it is beyond the scope of developing an improved body, this has been left for future research.

\subsection{Anchor Force}

\subsubsection{Test Setup}

The amount of force the crawler can generate to pull forth a load is limited by how much force each head can anchor. This in turn is determined by how much pressure the bladder material can contain and by how much it can expand. The latter factor being important as the more the bladder expands, the larger the surface area it has in contact with the pipe, thus the more traction it can gain in order to transfer force without slipping. This test setup consisted of one head of the crawler attached via a braided steel cable to a spring scale. The opposite end of the spring scale was attached to a manual winch, which in turn was attached to the ground. The head was inserted in a 36" long, 3" I.D. pipe and the winch was cranked, increasing the force on the head, until the head slipped in the pipe. The force just before the slippage was recorded as the maximum anchor force. The 
inflation pressure of the bladder was increased by $10 \mathrm{psi}$ for each successive test in order to gauge the anchor force at various pressures. The bladder material consisted of a heavy duty inner tube sized for a 26 " bicycle tire, with a diameter range of 1.95 " to 2.35 " in uninflated condition. The wall thickness of this tube is 0.135 " and it is made of butyl rubber. It was inflated to a maximum pressure of $70 \mathrm{psi}$.

\subsubsection{Results}

\begin{tabular}{|c|c|}
\hline Pressure (psi) & Average Force Anchored (lbs) \\
\hline 10 & 31.80 \\
\hline 20 & 63.60 \\
\hline 30 & 95.40 \\
\hline 40 & 127.20 \\
\hline 50 & 159.00 \\
\hline 60 & 190.90 \\
\hline 70 & 222.70 \\
\hline
\end{tabular}

Table 10: Anchor Force

The anchor force of a single head using this material would limit how far a crawler could travel due to the increasing drag from the umbilical as the distance traveled increases. Considering that each cylinder in the crawler is rated at an output of $132 \mathrm{lbs}$, the array of four cylinders could easily surpass the $222.7 \mathrm{lb}$ maximum anchor force. A separate thesis could be done on developing an improved method of anchoring this crawler in a pipe. Self- actuating mechanical methods of anchoring which do not require air would be ideal. This would allow for the elimination of two valves and greatly simplify programming.

\subsection{Pulling Force}

The configuration of this crawler is such that it pulls its payload forward in the expansion phase. Thus, the pulling force is equivalent to the maximum force the body can 
provide on outstroke. Force transfer on outstroke of the crawler can be calculated with knowledge of the force output of the cylinders and their angles by using kinematic calculations. The following table depicts the theoretical force output of the crawler if the body is completely straight.

\begin{tabular}{|c|c|c|}
\hline \multicolumn{3}{|c|}{ Theoretical Force Output (F=PA) } \\
\hline P & 250 & Ib/in2 \\
\hline D & 0.75 & in \\
\hline A & 0.44 & in2 \\
\hline F & 110.45 & $\mathrm{Ib}$ \\
\hline Overall & 441.8 & $\mathrm{Ib}$ \\
\hline
\end{tabular}

Table 11: Theoretical Linear Force Output

From simulation and observation of actual testing through an elbow, the angle of one cylinder relative to the axis of the one preceding it will always be smaller than $90^{\circ}$. Assuming an angle between cylinders of $89^{\circ}$, the effective thrust is calculated and depicted in the table below. Effective thrust in this case is equal to $F \sin (\theta)$, where $\theta$ represents the angle between the axis of one cylinder and the cylinder it acts upon [23].

\begin{tabular}{|c|c|c|}
\hline \multicolumn{3}{|c|}{ Angular Thrust } \\
\hline Maximum Angle & 89 & ${ }^{\circ}$ \\
\hline Angular Force (effective thrust) & 110.43 & $\mathrm{lb}$ \\
\hline Force Lost & 0.02 & $\mathrm{lb}$ \\
\hline Overall & 441.71918 & $\mathrm{lb}$ \\
\hline
\end{tabular}

Table 12: Theoretical Angular Force Output

In an effort to understand the force output on a part by part basis, an individual cylinder was evaluated over changing inflation pressures. The theoretical output of one cylinder was calculated and then compared to actual measurements of the force output. 


\begin{tabular}{|c|c|}
\hline \multicolumn{2}{|c|}{ Theoretical Force Output } \\
\hline Pressure (psi) & Force (Ib) \\
\hline 25 & 11.04 \\
\hline 50 & 22.09 \\
\hline 75 & 33.13 \\
\hline 100 & 44.18 \\
\hline 125 & 55.22 \\
\hline 150 & 66.27 \\
\hline 175 & 77.31 \\
\hline 200 & 88.36 \\
\hline 225 & 99.4 \\
\hline 250 & 110.45 \\
\hline
\end{tabular}

Table 13: Theoretical Output of Single Cylinder

Force outputs can be measured by attaching the cylinder to a jig with a digital scale on one end. It must be noted that in order to reach the 250 psi maximum pressure, a conventional compressor would not suffice. A large compressor with a tank size in the triple digits from an auto body shop was used. The plastic fittings at the cylinder ports were replaced with the stainless steel units in order to avoid failure at these pressures. A pressure gauge was installed at the base of the cylinder. Air is then provided to the cylinder; allowing it to outstroke and apply force to the scale until the gauge reads the set pressure. There are some losses due to internal friction of the cylinder; at $250 \mathrm{psi}$, the measured output is $0.64 \mathrm{lbs}$. below the theoretical output. This loss in force output is smaller than the force loss that would result from a 1 psi drop in pressure. 


\begin{tabular}{|c|c|}
\hline \multicolumn{2}{|c|}{ Measured Force Output } \\
\hline Pressure (psi) & Force (Ib) \\
\hline 25 & 11.00 \\
\hline 50 & 21.98 \\
\hline 75 & 32.95 \\
\hline 100 & 43.94 \\
\hline 125 & 54.91 \\
\hline 150 & 65.89 \\
\hline 175 & 76.87 \\
\hline 200 & 87.85 \\
\hline 225 & 98.82 \\
\hline 250 & 109.81 \\
\hline
\end{tabular}

Table 14: Measured Output of Single Cylinder

In order to test for force output of the entire robot, the crawler was placed in a longer jig consisting of a 3" diameter pipe attached to the digital scale via a support structure. This allows for mounting the crawler assembly on one side and having it push on the scale on the other. Each test was done at a given inflation pressure for the cylinders and the pressure was increased in 10 psi increments for each successive test. Exerting force on the scale while within a pipe allows the cylinders to change angle as they would when pulling a load. It should be noted that in an unplugging configuration, part of the umbilical would be a pressure hose. This could help right the robot as it expands, providing larger overall force transfer. Even without this aid, the crawler did not toggle significantly during expansion against the scale, leading to a very small loss of force output. 


\begin{tabular}{|c|c|}
\hline \multicolumn{2}{|c|}{ Measured Force Output } \\
\hline Pressure (psi) & Force (Ib) \\
\hline 25 & 43.98 \\
\hline 50 & 87.90 \\
\hline 75 & 131.79 \\
\hline 100 & 175.72 \\
\hline 125 & 219.61 \\
\hline 150 & 263.53 \\
\hline 175 & 307.42 \\
\hline 200 & 351.34 \\
\hline 225 & 395.23 \\
\hline 250 & 439.16 \\
\hline
\end{tabular}

Table 15: Measured Output of Crawler

\subsection{Dimensional Adaptability}

\subsubsection{Test Setup}

In order to test the adaptability of the designed crawler in the event of a dimension change in the pipelines, a test bed was constructed consisting of a 27 " long, 3" I.D. pipe followed by a reducer into a 60" long, 2" I.D. pipe, and ending in an enlarger back to an 11" long, 3" I.D. pipe. The crawler was inserted at the 27 " section of the test bed and cycled forth until the front head lined up with the end of the 11 " section on the opposite end. Measuring from initial position of the front head to the end, this translates to 80.94." The figure below is an image of the adaptability test bed.

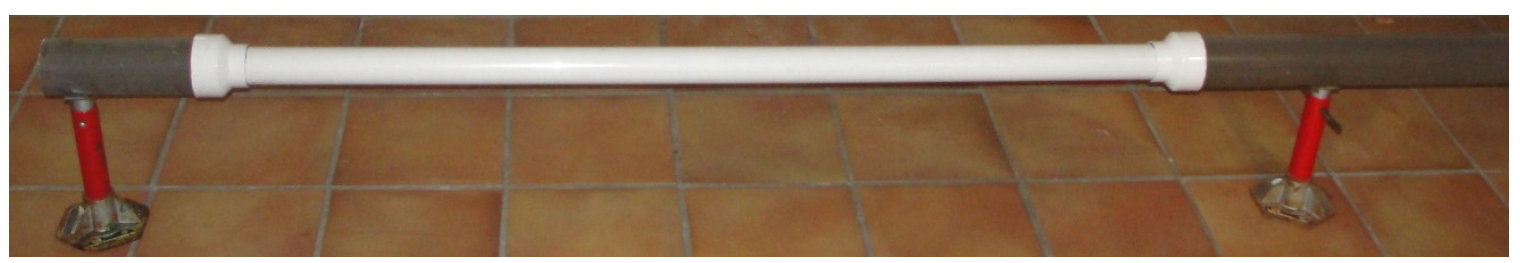

Figure 30: Adaptability Test Bed 


\subsubsection{Results}

Adaptability was first evaluated with the initial version of the PLC program and later evaluated with the modified program. It was important to observe if the conventional straight line programming scheme could handle sudden changes in pipeline diameter. The body was designed to handle the transition without physical impediment; however the program was designed around locomotion in a continuous diameter of pipe. Testing showed that an alternative programming scheme is not necessary in order to manage transitions in diameter. The results of the adaptability test with the initial program are presented below:

\begin{tabular}{|c|c|c|}
\hline \multicolumn{3}{|c|}{ Adaptability } \\
\hline Distance(in) & Time(s) & Speed (ft/hr) \\
\hline 80.94 & 132.53 & 183.21 \\
\hline 80.94 & 132.53 & 183.21 \\
\hline 80.94 & 132.55 & 183.19 \\
\hline 80.94 & 132.56 & 183.18 \\
\hline 80.94 & 132.56 & 183.18 \\
\hline 80.94 & 132.56 & 183.18 \\
\hline 80.94 & 132.54 & 183.20 \\
\hline 80.94 & 132.52 & 183.23 \\
\hline 80.94 & 132.52 & 183.23 \\
\hline 80.94 & 132.52 & 183.23 \\
\hline Average & 132.54 & 183.20 \\
\hline
\end{tabular}

Table 16: Adaptability Test with Initial Program

The transition into a reducer creates a slight reduction in speed as opposed to the expansion where the crawler simply comes out to the larger pipe without resistance. This led to the overall speed of the crawler decreasing by over $0.5 \mathrm{ft} / \mathrm{hr}$ on average. With the initial program tests complete, the modified program was developed and installed on the PLC. The adaptability testing was conducted once more with the new program. The results are presented below: 


\begin{tabular}{|c|c|c|}
\hline \multicolumn{3}{|c|}{ Adaptability } \\
\hline Distance(in) & Time(s) & Speed (ft/hr) \\
\hline 80.94 & 131.27 & 184.97 \\
\hline 80.94 & 131.27 & 184.97 \\
\hline 80.94 & 131.29 & 184.95 \\
\hline 80.94 & 131.29 & 184.94 \\
\hline 80.94 & 131.29 & 184.94 \\
\hline 80.94 & 131.27 & 184.98 \\
\hline 80.94 & 131.28 & 184.97 \\
\hline 80.94 & 131.25 & 185.00 \\
\hline 80.94 & 131.25 & 185.01 \\
\hline 80.94 & 131.26 & 184.99 \\
\hline Average & 131.27 & 184.97 \\
\hline
\end{tabular}

Table 17: Adaptability Test with Modified Program

As before, the modified version of the program presented an improvement in time. A time savings of approximately 1.3 seconds was realized, translating to an overall improvement of $1.77 \mathrm{ft} / \mathrm{hr}$. Reductions in overlap times ensured that the front would deflate sooner, allowing more time for the bladder to contract before the head entered the transition, thereby providing less resistance. 


\section{Discussions}

The goal of this thesis was to develop a body which would allow a robot to navigate and survive in the dimensional and radioactive conditions present within HLW pipelines. The main site of interest was the DOE Hanford site, where there are HLW pipelines with a 3 " ID, some 2" ID sections, and $90^{\circ}$ elbows. However, this device can be adapted to work with various pipeline dimensions and for different applications. The end goal for a crawler at Hanford would be to unplug pipes. No configuration for unplugging has been presented here, it is left to others to determine how they would adapt this crawler for their particular needs.

Pneumatic cylinders were used for the body because of the advantages they present in response, force output, and size. A methodology for sizing the device was determined and followed in order to achieve a balance between force output and overall size. Essentially, the largest possible cylinder bore that could pass through an elbow was determined and selected. The maximum possible stroke was selected similarly. The kinematics of the desired configuration were calculated and the cylinders were arrayed such that each cylinder is easily replaced via removal of four bolts and one pin, making the robot simple to repair. The final prototype was designed such that a regular machine shop can replicate it without need for expensive tooling or fixtures.

The device developed in this thesis was tested using pipes set up in various

configurations. In the category of straight line speed, the device was capable of a maximum linear speed of $185.51 \mathrm{ft} / \mathrm{hr}$. The maximum cornering speed was also measured, with the elbow being cleared in 60.5 seconds. Straight line force output topped 
out at a maximum of $439.16 \mathrm{lbs}$. This body also has the capacity to transition into a 2" pipe. The overall material cost of the prototype is $\$ 527.88$. However, machining took a total of 15 hours and 43 minutes. At a typical shop charge of $\$ 50 / \mathrm{hr}$. and the $43 \mathrm{~min}$ being charged as an hour, the cost of machining adds $\$ 800$. With more development time, accessories for unplugging and inspecting pipelines could be implemented, requiring that only the heads be modified. However, the goals set for this thesis have been met. 


\section{References}

[1] Washington River Protection Solutions, Tank Operations Contractor, 2012.

[2] Oregon Department of Energy, "Safely dealing with Hanford's high-level radioactive waste," Salem, OR, 2011.

[3] M. G. Thien, B. E. Wells and D. J. Adamson, "High-Level Waste Feed Certification in Hanford Double-Shell Tanks - 10083," in Waste Management 2010 Conference, Phoenix, Az, 2010.

[4] R. L. R. Gephart, "Hanford Tank Clean up: A Guide to Understanding the Technical Issues," 1995.

[5] D. Roelant, D. McDaniel, J. Varona and S. Gokaltun, "Unplugging of High Level Waste Transfer Pipelines," Miami, 2007.

[6] J. A. Matos, L. R. Brady and B. Posse, "Peristaltic Crawler for Removal of Radioactive Plugs," Miami, 2010.

[7] D. Roelant, D. McDaniel, J. Varona, S. Gokaltun, R. Patel and A. Awwad, "Evaluation of Innovative High-Level Waste Pipeline Unplugging Technologies," ARC, 2009.

[8] Inspector Systems, "Pipe Crawler- robots for video and laser inspection," [Online]. Available: www.inspector-systems.com/video_robots.html.

[9] M. Anderson, T. Ferrante, M. McKay and W. Willis, "Miniature Pipe Crawler Tractor". United States of America Patent 6035786, 22 October 1997.

[10] E. Martinson, M. Mark and W. Sheraz, "The Pipe Crawler," Florida Atlantic University, 2009.

[11] J. Boon, E. de Buda and M. Dolbey, "Pnuematically Operated Pipe Crawler". United States of America Patent 4372161, 4 May 1981.

[12] M. Hapstack, "Extendable Pipe Crawler". United States of America Patent 5018451, 5 Jan 1990. 
[13] T. Pribanic, A. Awwad, J. Crespo, D. McDaniel, J. Varona, S. Gokaltun and D. Roelant, "Design Improvement and Analysis of Innovative High Level Waste Pipeline Unplugging Technologies," WM2012 Conference, Pheonix, Arizona, 2012.

[14] L. P. Houssay, "Robotics and Radiation Hardening in the Nuclear Industry," University of Florida, 2000.

[15] W. Carlos, "Material Selection for Multi-Function Waste Tank Facility Tanks," Westinghouse Hanford Company, Richland, Washington, 1994.

[16] K. Vandergriff, "Designing Equipment for Use in Gamma Radiation Environments," U.S. Department of Energy, 1990.

[17] Mead Pneumatic Automation Components, Pneumatic Application and Reference Handbook, Chicago, 2005.

[18] MAC Valves, Bullet Valves Catalog, 2013.

[19] Clippard Instrument Laboratory, Inc. - USA, "Quick Exhaust Valve Cylinder Application," [Online]. [Accessed 2013].

[20] T. Pribanic, D. McDaniel, J. Varona and A. Awwad, "Evaluation and Development of Innovative High-Level Waste Pipeline Unplugging Technologies (Peristaltic Crawler)," April 2011.

[21] US Department of Energy, "Standard for the Selection of Non-Metallic Materials in Contact with Tank Waste," Richland, WA, 2011.

[22] E. Oberg, Machinery's Handbook, Industrial Press, 2012.

[23] Parker, "Hydraulic and Pneumatic Cylinder Appendix Application Engineering Data," p. 88.

[24] OMRON Corporation, "Zen V2 Units," 2011. [Online].

[25] A. Sample, D. Yeager, P. Powledge, A. Mamishev and J. Smith, "Design of and RFID-Based Battery-Free Programable Sensing Platform," IEEE Transactions on Instrumentation and Measurements, vol. 57, no. 11, pp. 2608-2615, Nov 2008.

[26] L. Chen, C. Ong, C. Neo, V. Varadan and V. Varadan, Microwave Electronics: Measurement and Materials Characterization, Chichester: John Wiley \& Sons Ltd, 
2004, pp. 496-503.

[27] HCET, "Plugging Prevention and Unplugging of Waste Transfer Pipelines," Miami, 2003.

[28] T. Pribanic, S. Gokaltun, D. McDaniel, J. Varona and D. Roelant, "Summary of Conceptual Designs for Two Pipeline Unplugging Methods," ARC, September 2009.

[29] M. Powell, G. Golcar and J. Geeting, "Retrieval Process Development and Enhancements Waste Simulant Composition and Defensibility," U.S. Department of Energy, September 1997.

[30] W. Zollinger and F. Carney, "Pipeline Blockage Unplugging and Locating Equipment," ANS 10th International Topical Meeting on Robotics and Remote Systems for Hazardous Environments, 2004.

[31] M. Moghaddam, M. Arbabtafti and A. Hadi, "In-Pipe Inspection Crawler Adaptable to the Pipe Interior Diameter," International Journal of Robotics and Animation, vol. 26, pp. 135-145, 2011. 


\section{Appendix: Modifications}

\subsection{Physical Modifications}

Upon initial testing of the crawler in a 3" I.D. pipe, it was found that the hinges allowed too much slop. Any attempt at cycling the crawler forward would result in the front head changing angle and the entire device would toggle in the pipe. In order to eliminate this, the speed of angular change had to be limited. Application of torsion springs at the hinges was considered, however, these would add too much mechanical complexity and manufacturing times/costs. A simple, rubber bushing was inserted into each hinge such that it applied pressure to the rod eye. With this in place, the speed of angular changes was reduced, such that force from an elbow would be necessary to cause the bodies to turn. With this, the crawler was able to move forward in a straight line and it did not create a problem in elbows. It should be noted that all of the above testing of the device was carried out with this modification in place.

Initial testing also revealed a tendency for bladders to inflate unevenly, and for them to rupture. The first issue can be mitigated via a process change in the bladder installation. Uneven inflation was addressed by cutting the material longer than the head and clamping it to one end of the head while stretched past the other end. This allows for the material to flow away from the clamp, over the free end, reducing the tendency for it to twist under clamping. Tape was wrapped over the central section of the bladder before clamping the other end. This reduced bulging toward the center of the bladder. 
Analysis of the disassembled heads and rupture points on the bladders revealed small edges on the heads were producing a slight amount of wear on the bladders each cycle, eventually leading to failure after several cycles. Eliminating this issue was accomplished by changing the finish on the heads. These were polished with a medium and then a fine grain steel wool, creating a smooth, mirror-like surface. However, this issue highlights the possibility of rupture due to sharp edges inside the pipes. This is yet another indication that the bladder system should be replaced with a more durable, mechanical solution. Using a bladder with a tougher outer layer could potentially mitigate the issue in lieu of such a modification.

\subsection{Program Modifications}

The initial form of the program written for the crawler used certain overlaps in cycles to avoid slippage. Essentially, the rear bladder would expand, followed by the body expanding, and then the front bladder would expand. At this point the rear and front are both inflated, before the rear releases and the body contracts. This overlap keeps the body from cycling before the appropriate bladder has anchored. The original program allowed for this overlap to last more than a second. In exchange for eliminating any chances of slippage, this added some time to the cycle and reduced speed. By adjusting the time tables to reduce this overlap, approximately $1.8 \mathrm{ft}$./hr. was gained in straight line speed and $0.20 \mathrm{ft} . / \mathrm{hr}$. in cornering. In the final time table, rear and body are inflated for approximately 3 seconds before the front turns on. At this point, there is an overlap lasting just 0.5 second before the rear releases and the body contracts. This cycle 
completes when the rear re-inflates with the body contracted, right before the next expansion cycle. The extend/collapse cycle takes about 6.5 seconds to complete. 